UNIVERSIDADE DE SÃO PAULO

FACULDADE DE MEDICINA DE RIBEIRÃO PRETO

VANESSA PATRÍCIA PEREIRA MOTOZO

Insegurança Alimentar e Nutricional domiciliar de famílias beneficiárias do Programa Bolsa Família no município de Ribeirão Preto, São Paulo.

Ribeirão Preto 
Insegurança Alimentar e Nutricional domiciliar de famílias beneficiárias do Programa Bolsa Família no município de Ribeirão Preto, São Paulo.

Versão Corrigida da dissertação apresentada em: 09 de abril de 2020

Dissertação apresentada à Faculdade de Medicina de Ribeirão Preto da Universidade de São Paulo para a obtenção do título de Mestre em Ciências.

Área de concentração: Saúde Pública

Orientador: Prof. Dr. Laercio Joel Franco

Ribeirão Preto 
Autorizo a reprodução e divulgação total ou parcial deste trabalho, por qualquer meio convencional ou eletrônico, para fins de estudo e pesquisa, desde que citada a fonte.

Motozo, Vanessa Patrícia Pereira

Insegurança Alimentar e Nutricional domiciliar de famílias beneficiárias do Programa Bolsa Família no município de Ribeirão Preto, São Paulo. Ribeirão Preto, 2020.

81 p. : il.; $30 \mathrm{~cm}$

"Versão corrigida. A versão original encontra-se disponível tanto na Biblioteca da Unidade que aloja o Programa, quanto na Biblioteca Digital de Teses e Dissertações da USP (BDTD)")

Orientador: Franco, Laercio Joel.

1. Segurança Alimentar e Nutricional. 2. Direitos Humanos. 3. Políticas Públicas. 4. Iniquidade social. 5. Estado nutricional. 


\section{FOLHA DE APROVAÇÃO}

Nome: MOTOZO, Vanessa Patrícia Pereira

Título: Insegurança Alimentar e Nutricional domiciliar de famílias beneficiárias do Programa Bolsa Família no município de Ribeirão Preto, São Paulo.

Dissertação apresentada à Faculdade de Medicina de Ribeirão Preto da Universidade de São Paulo para a obtenção do título de Mestre em Ciências.

Aprovado em:

Banca examinadora:

Prof. (a) Dr. (a):

Instituição:

Julgamento:

Prof. (a) Dr. (a):

Instituição:

Julgamento:

Prof. (a) Dr. (a):

Instituição:

Julgamento: 
"O presente trabalho foi realizado com o apoio da Coordenação de Aperfeiçoamento de Pessoal de Nível Superior - Brasil (CAPES) - Código de Financiamento 001" 


\section{DEDICATÓRIA}

À minha mãe Ana, com amor e gratidão, por sempre me incentivar, apoiar e ser o meu porto seguro, meu espelho, modelo de conduta e vida.

Ao meu pai Hilton, minha avó Teonília e aos meus irmãos, Lane e Hiltin, que amo incondicionalmente, por me fortalecerem durante todo desenvolvimento desta pesquisa com palavras de conforto, apoio, carinho, torcida e orações. 


\section{AGRADECIMENTOS}

Primeiramente agradeço a DEUS, pela graça de cursar esta pós-graduação e por ser a base da minha conquista. Acima de tudo, pela força, proteção, paciência e determinação concedidas à minha pessoa. Peço que me dê sabedoria para conquistar muito mais!

Aos meus pais, Ana e Hilton, por todo amor, cuidado, incentivo e por acreditarem em minhas escolhas, esforçando-se junto a mim para que eu alcançasse meus objetivos.

Aos meus irmãos, Lane e Hiltim, pelo companheirismo, força, paciência, apoio e orações.

A toda minha família, em especial a minha avó Teoníla, pela motivação e por me sustentar em oração.

A Isabela Sobral e Cesário Souza que foram os primeiros incentivadores para que este sonho se tornasse realidade. Deus os abençoe por tudo o que fizeram por mim.

Ao Prof. Dr. Laercio Joel Franco, pela oportunidade, por acreditar em mim, pela atenção, paciência, orientação, disponibilidade e solicitude ao longo desse período.

A Profa Dra Luciana Cisoto, pela orientação e ensinamento durante todo o desenvolvimento desta pesquisa, pela paciência, disponibilidade, compreensão e experiência compartilhada.

Aos professores Dr. Amaury Lelis Dal Fabbro, Dra Ana Vitória Barban Margutti e Dra Carla Regina de Souza, pelas contribuições no exame de qualificação.

A todos os professores que fizeram parte desta maravilhosa trajetória, pelos ensinamentos que não serão esquecidos.

A Secretaria do Programa de Pós-Graduação em Saúde Pública, Faculdade de Medicina de Ribeirão Preto, Universidade de São Paulo, na pessoa da Paula e Sérgio, pela atenção e solicitude.

Aos meus amigos, pelo acolhimento, atenção, escuta, partilhas e consolo nos momentos difíceis.

A todas equipes da USF. Maria Casagrande, USF. Paulo Gomes Romeo, USF. Jamil Cury, USF. Paiva, UBS. Dom Mielle, UBS. José Sampaio e USF. Eugênio Lopes, em especial, as gerentes de unidade e os Agentes Comunitários de Saúde, pelo apoio e contribuição durante a coleta de dados.

A todas as pessoas que direto ou indiretamente contribuíram para a elaboração desta pesquisa.

A todas as dificuldades que enfrentei, elas foram adversárias dignas e tornaram minhas vitórias muito mais saborosas. 


\section{EPÍGRAFE}

"A falta de amor é a maior de todas as pobrezas"

- Madre Teresa de Calcutá 


\section{RESUMO}

MOTOZO, Vanessa Patrícia Pereira. Insegurança Alimentar e Nutricional domiciliar de famílias beneficiárias do Programa Bolsa Família no município de Ribeirão Preto, São Paulo. 2020. 81f. Dissertação (Mestrado em Saúde Pública) - Faculdade de Medicina de Ribeirão Preto, Universidade de São Paulo, Ribeirão Preto, 2020.

A Insegurança Alimentar e Nutricional (IAN) consiste na preocupação perante a incerteza da disponibilidade do alimento, na convivência com a fome ou na ingestão de uma dieta com baixa qualidade nutricional, insuficiente para suprir as necessidades básicas do indivíduo. Assim, o objetivo deste estudo foi avaliar as famílias beneficiárias do Programa Bolsa Família segundo a condição de Insegurança Alimentar e Nutricional no Distrito Sanitário Oeste do município de Ribeirão Preto, São Paulo. Trata-se de um estudo descritivo do tipo inquérito realizado através da aplicação de entrevista com 246 titulares do Programa Bolsa Família para coleta de variáveis socioeconômicas, demográficas e IAN diagnosticada por meio da Escala Brasileira de Insegurança Alimentar (EBIA). Também foram coletados peso corporal (atual) e altura (atual) dos titulares e 206 crianças menores de sete anos de idade para caracterização do estado nutricional, o qual foi determinado pelos índices estatura para idade, peso para idade, peso para estatura e índice de massa corporal para idade (OMS, 2006, 2007). Identificou-se que a condição de IAN atingia 94,3\% das famílias, destas 27,6\% apresentavam IAN moderada e 25,6\% IAN grave. A partir da análise socioeconômica e demográfica, observou-se predomínio de titulares do sexo feminino $(97,6 \%)$, cor/raça parda $(54,9 \%)$, baixa escolaridade $(53,3 \%)$, com companheiro (a) (52\%) e desempregados (64,6\%). Verificou-se maior proporção de famílias beneficiarias pertencentes ao estrato social intermediário (54\%), com recebimento mensal de até 2 salários mínimo (95\%), residentes em casa própria (62,6\%) com até 4 moradores $(61,4 \%)$ e com crianças menores de 7 anos $(57,7 \%)$. Quanto às famílias, 60,4\% recebem o benefício há mais de 48 meses, 74,3\% recebem duzentos reais ou menos e $70,7 \%$ utilizam a maior proporção para aquisição de alimentos. Em relação ao estado nutricional, o excesso de peso foi verificado em 73,6\% dos titulares e 25,5\% das crianças. Diante os resultados encontrados, urge a necessidade de estratégias de promoção de Educação Alimentar e Nutricional direcionada a essa população.

Palavras-chave: Segurança Alimentar e Nutricional. Direitos Humanos. Políticas Públicas. Iniquidade social. Estado nutricional. 


\begin{abstract}
MOTOZO, Vanessa Patrícia Pereira. Household Food and Nutritional Insecurity of families benefiting from the Bolsa Família Program in the city of Ribeirão Preto, São Paulo. 2020. 81f. Dissertação (Mestrado em Saúde Pública) - Faculdade de Medicina de Ribeirão Preto, Universidade de São Paulo, Ribeirão Preto, 2020.
\end{abstract}

The Food Insecurity and Nutrition (IAN) is the concern about the uncertainty of food availability, in living with hunger or eating a diet with low nutritional quality, insufficient to meet the basic needs of the individual. Thus, the objective of this study was to evaluate the families benefiting from the Bolsa Família Program according to the condition of Food Insecurity and Nutrition in the Western Sanitary District of the municipality of Ribeirão Preto, São Paulo. This survey was conducted through interviews with 246 family head of the Family Grant Program to collect socioeconomic, demographic and IA diagnosed by d the Brazilian Food Insecurity Scale (EBIA). Body weight (current) and height (current) of holders and 206 children under seven years of age were also collected to characterize the nutritional status, which was determined by height-for-age, weight-for-age, weight-for-height and body-massfor-age indices (WHO 2006 and 2007). It was identified that the condition of IAN reached $94.3 \%$ of the families, of these $27.6 \%$ had moderate IAN and $25.6 \%$ severe IAN. From the socioeconomic and demographic analysis, there was a predominance of female members (97.6\%), color /race mulattos (54.9\%), low education $(53.3 \%)$, with partner $(52 \%)$ and unemployed (64.6\%). There was a higher proportion of beneficiary families belonging to the intermediate social strata (54\%), with monthly income of up to 2 minimum wages (95\%), residing in their own home $(62.6 \%)$ with up to 4 residents $(61.4 \%)$ and with children under 7 years old $(57.7 \%)$. As for families, $60.4 \%$ have received the benefit for more than 48 months, $74.3 \%$ receive two hundred reais or less and $70.7 \%$ use the highest proportion for purchasing food. Regarding nutritional status, overweight was observed in $73.6 \%$ of the holders and $25.5 \%$ of the children. In view of the results found, there is an urgent need for strategies to promote Food and Nutrition Education aimed at this population.

Keywords: Food and Nutritional Security. Human rights. Public policy. Social inequity. Nutritional status. 


\section{LISTAS DE ILUSTRAÇÕES}

Figura 1 - Distritos de Saúde do município de Ribeirão Preto, São Paulo........... 30

Quadro 1 - Classificação do estado nutricional das crianças segundo os índices antropométricos. 


\section{LISTA DE TABELAS}

Tabela 1 - Pontos de corte segundo nível de Segurança/Insegurança Alimentar e Nutricional

Tabela 1 - Caracterização da Insegurança Alimentar e Nuricional das famílias beneficiárias do Programa Bolsa Família no Distrito Sanitário Oeste do município de Ribeirão Preto. Ribeirão Preto, SP, 2020.

Tabela 2 - Características dos titulares do Programa Bolsa Família residentes no Distrito Sanitário Oeste do município de Ribeirão Preto. Ribeirão Preto, SP, 2020.

Tabela 3 - Caracterização socioeconômica e demográfica das famílias beneficiárias do Programa Bolsa Família, residentes no Distrito Sanitário Oeste do município de Ribeirão Preto. Ribeirão Preto, SP, 2020 .

Tabela 4 - Informações referentes ao benefício do Programa Bolsa Família relatadas pelas famílias estudadas. Ribeirão Preto, SP, 2020.

Tabela 5 - Caracterização do estado nutricional das crianças menores de sete anos de idade pertencentes às famílias beneficiárias do Programa Bolsa Famílias, residentes no Distrito Oeste do Município de Ribeirão Preto. Ribeirão Preto, SP, 2020.

Tabela 6 - Prevalência e Razão de Prevalência (RP) bruta e ajustada por regressão log-binomial de Insegurança Alimentar e Nutricional, segundo características socioeconômicas, demográficas e informações relacionadas às famílias beneficiárias do Programa Bolsa Família, residentes no Distrito Sanitário Oeste do município de Ribeirão Preto. Ribeirão Preto, SP, 2020........................... 


\section{LISTAS DE ABREVIATURAS E SIGLAS}

$\begin{array}{ll}\text { SA } & \text { Segurança Alimentar } \\ \text { DEP } & \text { Desnutrição Energética Proteica } \\ \text { DHAA } & \text { Direito Humano à Alimentação Adequada } \\ \text { PIDESC } & \text { Pacto Internacional dos Direitos Econômicos, Sociais e Culturais } \\ \text { SAN } & \text { Segurança Alimentar e Nutricional } \\ \text { LOSAN } & \text { Lei Orgânica da Segurança Alimentar e Nutricional } \\ \text { IA } & \text { Insegurança Alimentar } \\ \text { PNAD } & \text { Pesquisa Nacional por Amostra de Domicílios } \\ \text { EBIA } & \text { Escala Brasileira de Insegurança Alimentar } \\ \text { IAL } & \text { Insegurança Alimentar Leve } \\ \text { IAM } & \text { Insegurança Alimentar Moderada } \\ \text { IAG } & \text { Insegurança Alimentar Grave } \\ \text { MDS } & \text { Ministério de Desenvolvimento e Combate a Fome } \\ \text { PBF } & \text { Programa Bolsa Família } \\ \text { CadÚnico } & \text { Cadastro único } \\ \text { UBDS } & \text { Unidade Básica Distrital de Saúde } \\ \text { UBS } & \text { Unidade Básica de Saúde } \\ \text { CSE } & \text { Centro Saúde Escola } \\ \text { USF } & \text { Unidade de Saúde da Família } \\ \text { CMSC } & \text { Centro Médico Social Comunitário } \\ \text { TCLE } & \text { Termo de Consentimento Livre e Esclarecido } \\ \text { CEP } & \text { Comitê de Ética em Pesquisa } \\ \text { CAAE } & \text { Certificado de Apresentação para Apreciação Ética } \\ \text { CONEP } & \text { Comissão Nacional de Ética em Pesquisa } \\ \text { ACS } & \text { Agente Comunitário de Saúde } \\ \text { VD } & \text { Visita Domiciliar } \\ \text { PACS } & \text { Programa de Agentes Comunitários de Saúde } \\ \text { BF } & \text { Bolsa Família } \\ \text { CCEB } & \text { Critério de Classificação Econômica Brasileira } \\ \text { ABEP } & \text { Associação Brasileira de Empresas de Pesquisa } \\ \text { SISVAN } & \text { Sistema de Vigilância Alimentar e Nutricional } \\ \text { P/I } & \text { Peso para Idade } \\ \text { E/I } & \text { Estatura para Idade } \\ \text { IMC/I } & \text { Índice de Massa Corpórea para Idade } \\ \text { P/E } & \text { Peso para Estatura } \\ \text { OMS } & \text { Organização Mundial da Saúde } \\ \text { POF } & \text { Pesquisa de Orçamentos Familiares } \\ \text { PNS } & \text { Pesquisa Nacional de Saúde } \\ \text { IBASE } & \text { Instituto Brasileiro de Análises Sociais e Econômicas } \\ \text { IBGE } & \text { Instituto Brasileiro de Geografia e Estatística } \\ \text { VIGITEL } & \text { Vigilância de Doenças Crônicas por Inquérito Telefônico } \\ \text { USP } & \text { Universidade de São Paulo } \\ & \end{array}$




\section{SUMÁRIO}

1 INTRODUÇÃ

1.1 Histórico da Segurança Alimentar................................................................ 15

1.2 Direito Humano a Alimentação Adequada e conceito de Segurança Alimentar e Nutricional.................................................................. 16

1.3 Insegurança Alimentar e Nutricional....................................................... 17

1.4 Programa Bolsa Família.................................................................................. 19

1.4.1 Tipos de benefício do Programa Bolsa Família........................................ 22

1.4.2 Condicionalidades do Programa do Bolsa Família..................................... 23

1.5 Transição Nutricional.................................................................................... 24

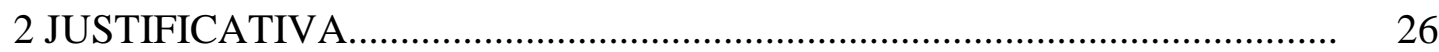

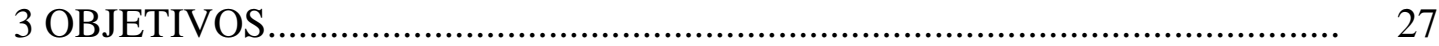

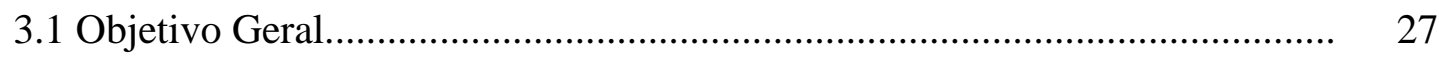

3.2 Objetivos específicos............................................................................ 27

4 CASUÍSTICA E MÉTODOS............................................................. 28

4.1 Modelo do estudo.............................................................................. 28

4.2 Local do estudo.................................................................................... 28

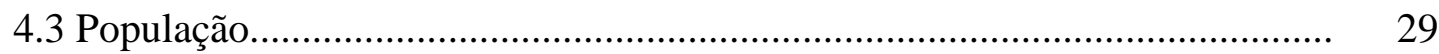

4.3.1 População de referência............................................................................ 29

4.3.2 População de esttudo.................................................................................. 29

4.3.2.1 Critérios de inclusão........................................................................... 29

4.3.2.2 Critérios de exclusão............................................................................... 29

4.4 Cálculo amostral.................................................................................. 30

4.5 Aspéctos éticos............................................................................... 31

4.6 Análise crítica dos riscos/desconfortos e benefícios..................................... 31

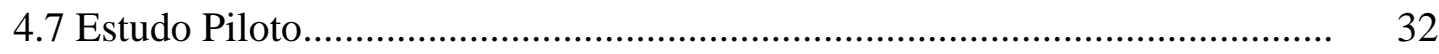

4.8 Coleta de dados......................................................................................... 32

4.8.1 Seleção dos participantes do estudo.......................................................... 32

4.8.2 Contato com as famílias selecionadas....................................................... 33

4.8.3 Período de coleta de dados............................................................................ $\quad 34$ 
4.8.4 Instrumento utilizado para coleta de dados

4.8.4.1 Escala Brasileira de Insegurança Alimentar........................................... 35

4.9 Avaliação do estado nutricional de crianças e titulares do benefício.............. 37

4.10 Processamento dos dados e Análise estatítica............................................ 40

4.11 Limitações do estudo............................................................................. 40

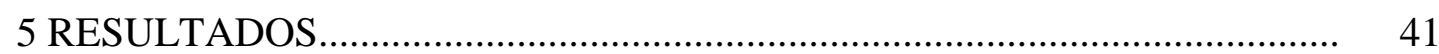

5.1 Insegurança Alimentar e Nutricional........................................................... 41

5.2 Caracterização socioeconômica e demográfica............................................ 41

5.3 Bolsa Família e recebimento de outros benefícios.......................................... 45

5.4 Estado nutricional das crianças................................................................ 46

6 DISCUSSÃO ................................................................................ 50

6.1 Insegurança Alimentar e Nutricional........................................................ $\quad 50$

6.2 Caracterização socioeconômica e demográfica............................................. 52

6.3 Bolsa Família e recebimento de outros benefícios.......................................... 58

6.4 Estado nutricional das crianças.................................................................... 60

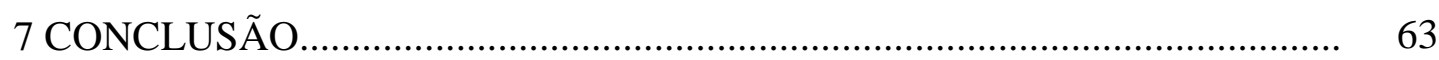

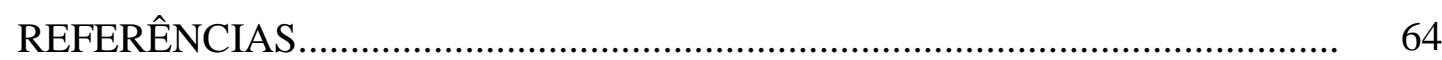

ANEXO I - Concordância com a realização do projeto nas unidades de saúde Secretaria Municipal de Saúde de Ribeirão Preto, São Paulo............................. $\quad 72$

ANEXO II - Aprovação pelo CEP Centro Saúde Escola da Faculdade de Medicina de Ribeirão Preto - FMRP/USP...................................................... $\quad 73$

APÊNDICE I - Termo de Consentimento Livre e Esclarecido - TCLE............... 74

APÊNDICE II - Questionário................................................................... $\quad 75$ 


\section{INTRODUÇÃO}

\subsection{Histórico da Segurança Alimentar}

Há décadas a Segurança Alimentar (SA) é tema presente nas agendas políticas de vários países. O surgimento de ideais proeminentes, movimentos e estatutos, luta contra a fome e a necessidade de gerar um estado de SA e bem estar nutricional se mostraram como grandes desafios no ideário das sociedades civis, como também para os poderes públicos (VALENTE, 2002; IPEA, 2014; MAGALHÃES, 2014).

Inicialmente, a SA foi vinculada à perspectiva de soberania alimentar, relacionada com a capacidade de cada país produzir alimentos suficientes para sua população e manter estoques mínimos para situações de calamidades, como desastres e guerras (PINHEIRO, 2008; IPEA, 2014; MAGALHÃES, 2014). Este conceito foi bastante empregado na segunda metade do século passado, principalmente no pós-guerra, onde os países devastados, principalmente os localizados no continente Europeu, precisavam garantir a alimentação de sua população (BELIK, 2003; MAGALHÃES, 2014).

No Brasil, as iniciativas relacionadas à SA foram reconhecidas a partir do quadro de fome e desnutrição que o país apresentava (PINHEIRO, 2008). A fome passou a ser entendida como um problema de saúde pública a partir da década de 1930, período em que se iniciava no país, o processo de urbanização e industrialização, tendo como característica do perfil epidemiológico nutricional brasileiro, a elevada ocorrência de doenças nutricionais relacionadas à miséria, à pobreza, à exclusão social e ao atraso econômico, patenteadas na época pela Desnutrição Energética Protéica (DEP) e pelas carências nutricionais específicas, como as deficiências de vitamina A (hipovitaminose A), ferro (anemia ferropriva) e de iodo (crescimento da glândula tireoide) (VASCONCELOS, 2005).

A definição de SA seguiu até a década de 70 vinculada à política de produção de alimentos, assinalada pela crise de escassez de alimentos, que ocorreu de 1972 a 1974 (VALENTE, 2002; PINHEIRO, 2008). Contudo, após superação da crise, verificou-se que os problemas nutricionais existentes, em especial a fome e a desnutrição, estavam mais associados às questões relacionadas à demanda e à distribuição de alimentos, do que à baixa produção (VALENTE, 2002; MAGALHÃES, 2014).

Na década de 1980 a 1990 constatou-se que somente o abastecimento de alimentos não solucionaria a carência nutricional apresentada pela população mundial. Entretanto, na I Conferência Nacional de Alimentação e Nutrição realizada em 1986, houve uma evolução no 
conceito de SA, tendo sua definição ampliada, acrescentando o acesso universal aos alimentos, o aspecto nutricional associado à disponibilidade e continuidade, enfatizando as questões relativas à qualidade, à composição, e ao aproveitamento biológico, além da prerrogativa básica para a condição de cidadania (VALENTE, 2002; COLUCCI; TONIN, 2006; MAGALHÃES, 2014).

Em 1994 foi realizada em Brasília, a I Conferência Nacional de Segurança Alimentar que instituiu eixos e prioridades para a formulação de políticas públicas e recuperação da cidadania, através do acesso aos alimentos (CONSEA, 1995). Dois anos depois, foi realizada em Roma, a Cúpula Mundial de Alimentação, na qual se discutiu o direito à alimentação enquanto um direito humano. Desta conferência resultou a Declaração de Roma para a SA Mundial e o Plano de Ação da Cúpula Mundial (FAO, 1996). Em 2000, foi aprovada a Declaração do Milênio das Nações Unidas, com metas objetivas para a erradicação da extrema pobreza, fome da população mundial e da mortalidade infantil (COLUCCI; TONIN, 2006). Posteriormente, no ano de 2004, em Olinda, Pernambuco, é realizada a II Conferência Nacional de Segurança Alimentar e Nutricional, onde se nota a inclusão do aspecto nutricional, corroborando a evolução clara da questão da segurança alimentar associada à nutrição (CNSAN, 2004; COLUCCI; TONIN, 2006).

\subsection{Direito Humano a Alimentação Adequada e conceito de Segurança Alimentar e Nutricional}

Ao longo dos anos, o Direito Humano à Alimentação Adequada (DHAA) vem sendo construído e consolidado, tendo como ponto de partida a Declaração Universal dos Direitos Humanos, promulgada em 1948 pela Organização das Nações Unidas (ONU), no qual estabelece que "Toda a pessoa tem direito a um nível de vida suficiente para lhe assegurar e à sua família, a saúde e o bem-estar, principalmente quanto à alimentação, ao vestuário, ao alojamento, à assistência médica..." (ONU, 1948, p. 6).

Posteriormente, em 1966 o Artigo 11 do Pacto Internacional dos Direitos Econômicos, Sociais e Culturais (PIDESC) reassegurou esse conceito e acrescentou que todas as pessoas têm direito "a uma melhoria continua de suas condições de vida", bem como, estarem livres da fome (BRASIL, 1992, Artigo 11, $\S 1^{\circ}$ e $2^{\circ}$ ). No mesmo ano, durante a Cúpula Mundial de Alimentação, os Estados Membros solicitaram uma melhor definição dos direitos relacionados à alimentação e que fossem propostas estratégias para implantação e realização do mesmo (SIQUEIRA et al., 2014). Em resposta, no ano de 1999 o Comitê de Direitos 
Econômicos, Sociais e Culturais do Alto Comissariado de Direitos Humanos da ONU, divulgaram o comentário geral $\mathrm{n}^{\circ} 12$, onde ficou instituído que o DHAA é realizado

\begin{abstract}
quando cada homem, mulher e criança, sozinho ou em companhia de outros, tem acesso físico e econômico, ininterruptamente, à alimentação adequada ou aos meios para sua obtenção. $\mathrm{O}$ direito à alimentação adequada não deverá, portanto, ser interpretado em um sentido estrito ou restritivo, que o equaciona em termos de um pacote mínimo de calorias, proteínas e outros nutrientes específicos (ONU, 1999).
\end{abstract}

No Brasil, a validação do PIDESC ocorreu em 1992, no qual o Estado Brasileiro assumiu a incumbência de respeitar, proteger, promover e prover o DHAA (SIQUEIRA et al., 2014). Anos depois, após extenso processo de mobilização social no país, foi aprovada em 2010 a Emenda Constitucional $\mathrm{n}^{\circ} 64$, que reconheceu a alimentação como um direito social de toda a população (BRASIL, 2010).

Assim, o DHAA pertence a todos, de forma única e exclusiva, por nascerem e integraremse à espécie humana (ONU, 1948). Constitui-se em um direito humano básico, imprescindível e inalienável, sem o qual é inviável discutir ou concretizar os demais direitos, visto que sua concretização é indispensável para o direito à vida e sua garantia deve ser assegurada pelo Estado através de políticas públicas de Segurança Alimentar e Nutricional. (TEO et al., 2017)

Atualmente, o conceito de Segurança Alimentar e Nutricional (SAN), aprovado na II Conferência Nacional de Segurança Alimentar e Nutricional e inserido na Lei $n^{\circ} 11.346$ - Lei Orgânica de Segurança Alimentar e Nutricional (LOSAN) - é definido como

\footnotetext{
a realização do direito de todos ao acesso regular e permanente a alimentos de qualidade, em quantidade suficiente, sem comprometer $\mathrm{o}$ acesso a outras necessidades essenciais, tendo como base práticas alimentares promotoras de saúde que respeitem a diversidade cultural e que sejam ambiental, cultural, econômica e socialmente sustentáveis (BRASIL, 2006).
}

Nesse contexto a SAN vem sendo considerada como um indicador de saúde essencial, visto que seu comprometimento no nível domiciliar tem evidenciado graves repercussões nas condições de saúde e nutrição das populações atingidas (OLIVEIRA et al., 2017).

\title{
1.3 Insegurança Alimentar e Nutricional
}

A violação do DHAA seguindo os princípios da SAN resulta na Insegurança Alimentar e Nutricional (IAN), na qual há preocupação e/ou angústia perante a incerteza da disponibilidade do alimento no dia a dia, na convivência com a fome ou na ingestão de uma dieta monótona, com baixa qualidade nutricional e insuficiente para suprir as necessidades básicas do indivíduo (MONTEIRO; SOUZA; PINHO, 2014; BEZERRA; PEDRAZA, 2015; SABOIA; SANTOS, 2015). 
A IAN é um fenômeno complexo e multidimensional de determinação multicausal (BEZERRA; OLINDA; PEDRAZA, 2017) que cresce de forma contínua, se desdobrando em diferentes níveis, ao passo que pioram as condições econômicas (BEZERRA; PEDRAZA, 2015). A princípio é experimentada em nível domiciliar e, quando agravada, em nível individual. Inicia-se pelos adultos que começam a omitir refeições, ou diminuir as porções dos alimentos e, por último, as crianças passam a vivenciar as mesmas experiências, indicando uma piora da situação no âmbito familiar (BRASIL, 2014).

Suas consequências possuem relação direta com a carência de qualidade e quantidade alimentar, sobretudo para os grupos mais vulneráveis, podendo cooperar para a mortalidade infantil, baixo peso ao nascer, prejuízo ao desenvolvimento físico e mental, mortalidade materna (SABOIA; SANTTOS, 2015) diminuição do desempenho escolar e evasão (RAMALHO et al., 2016).

Estudos mostram que a vulnerabilidade à situação de IAN é notada especialmente nos domicílios de baixa renda (OLIVEIRA et al., 2017; PEDRAZA et al., 2017; SUZART et al., 2017) onde a disponibilidade ou acesso aos alimentos são insuficientes, tendo desigual distribuição entre os moradores ( WEBB et al., 2006; SALLES-COSTA et al., 2008). Porém, de acordo com Ferreira et al. (2014) a renda precisa ser com compreendida como uma condição associada, não exclusiva.

Em vista disso, estudos evidenciam associação de IAN com baixa escolaridade, cor de pele parda/preta (BARROS et al., 2016; OLIVEIRA et al., 2017), composição familiar, características da moradia, condições sanitárias do domicílio, ser beneficiário do Programa Bolsa Família (BEZERRA; OLINDA; PEDRAZA, 2017; OLIVEIRA et al., 2017), deficiência nas condições de saneamento básico, qualidade da água, acesso precário à educação e saúde, desemprego, concentração de terra e outros que influenciam e comprometem de forma direta a qualidade de vida da população (FERREIRA et al., 2014; BEZERRA; OLINDA; PEDRAZA, 2017), em especial em famílias cuja composição possuem crianças e gestantes (OLIVEIRA et al., 2017).

Considerando as consequências da IAN é essencial identificar sua magnitude para que sejam adotadas as providências cabíveis para seu enfrentamento. Nessa perspectiva, de acordo com Belik (2013), mundialmente, mais de 900 milhões de pessoas estão em situação de IAN. No Brasil, a Pesquisa Nacional por Amostra de Domicílio (PNAD) realizou o primeiro levantamento no país, no qual se constatou que 34,8\% dos domicílios particulares estavam em IAN, alcançando 72 milhões de pessoas (IBGE, 2006a). As PNADs seguintes, realizadas em 
2009 e 2013, apontaram decréscimo dos domicílios em situação de IAN, representando 30,2 e $22,6 \%$ respectivamente (IBGE, 2014).

Entretanto, pesquisa recente evidenciou que a situação de IAN presente no país se agravou. Com o objetivo de descrever as mudanças no estado de SAN no Brasil antes e durante a sua mais recente crise financeira e política, pesquisadores notificam o aumento da IAN para 51,4\% afetando severamente a população mais pobre (SOUZA et al., 2019).

Tendo em vista que a baixa renda familiar é um importante fator de risco para a IAN, pesquisas realizadas em diferentes regiões do Brasil encontraram maiores prevalências de IAN entre as populações mais carentes, sendo verificado que quando realizadas com beneficiários do PBF, a prevalência é ainda maior. Nesse seguimento, Salles-Costa et al. (2008) em um estudo realizado com uma amostra representativa de população de baixa renda situada em Duque de Caxias, região metropolitana do Rio de Janeiro, verificaram que 53,8\% de famílias analisadas, apresentavam algum grau de IAN, destas 6,3\% em IAN grave.

Prevalências acima de 70\% de IAN foram encontradas em famílias beneficiárias do PBF de diferentes regiões do país (ANSCHAU; MATSUO; SEGALL-CORRÊA, 2012; MAGRANI et al., 2012; SILVA et al., 2012; SUZART et al., 2017). Também foi verificada esta condição em 91,2\% das famílias residentes em assentamentos de Maceió, Alagoas, beneficiárias do PBF (CABRAL et al., 2013).

Revisão sistemática de literatura recente, com metanálise de artigos científicos sobre SAN desenvolvidos no Brasil, publicados de 2004 a 2013 apontou uma média ponderada de 76,6\% de IAN para serviços de saúde/beneficiários do PBF (BEZERRA; OLINDA; PEDRAZA, 2017).

\subsection{Programa Bolsa Família}

Com o propósito de combater a fome e a pobreza no país, garantir o DHAA e promover a SAN, o governo brasileiro criou em 2003, o Programa Fome Zero (NASCIMENTO et al., 2017). Com a criação desse programa, ansiou-se estruturar ações capazes de garantir níveis mínimos de renda às famílias, como também apresentar propostas, algumas de cunho estrutural e outras emergenciais, para melhorar a condição de vida e reduzir a dependência da população (SILVA; GROSSI; FRANÇA, 2010; CABRAL et al., 2014). Desta forma, em outubro de 2003 foi criado por meio da Medida Provisória $\mathrm{n}^{\circ} 132$, que posteriormente foi convertida na Lei $\mathrm{n}^{\circ}$ 10.836, o Programa Bolsa Família (PBF) (BRASIL, 2018) objetivando unificar a gestão e execução de programas sociais de transferência de renda preexistentes, 
sendo eles o Bolsa Alimentação, Bolsa Escola, Auxílio Gás e o Cartão Alimentação (BRASIL, 2004; BARBOSA et al., 2014; CABRAL et al., 2014).

O PBF tem como intuito reduzir a pobreza, a fome e fomentar a inclusão social das famílias vítimas da desigualdade social que assola o país (SUZART et al., 2017), bem como, promover a SAN e o acesso aos direitos sociais básicos (saúde, alimentação, educação e assistência social) e romper o ciclo intergeracional da pobreza (CARMO et al., 2016; BRASIL, 2020). Dessa forma, o programa atua a partir da articulação de três dimensões: a) alívio imediato da pobreza por meio da transferência direta de renda; b) promoção do acesso aos direitos sociais básicos com a fixação de uma agenda de compromissos associados à saúde e educação; e c) capacidade de integrar e articular várias políticas sociais com o intuito de incentivar o desenvolvimento das famílias, contribuindo para superação da situação de vulnerabilidade e pobreza apresentada (BRASIL, 2020).

Este programa consiste na transferência direta de renda às famílias em situação de extrema pobreza (renda per capita mensal de até $\mathrm{R} \$ 89,00$ mensais) e pobreza (renda per capita mensal entre $\mathrm{R} \$ 89,01$ e $\mathrm{R} \$ 178,00)$, desde que tenham em sua composição crianças ou adolescentes de 0 a 17 anos de idade e gestantes (BRASIL, 2020).

A inserção das famílias no PBF é feita mediante inscrição no Cadastro Único (CadÚnico), sob responsabilidade da gestão municipal. A seleção é realizada por meio de um sistema informatizado, a partir dos dados informados pelas famílias no CadÚnico e das regras do programa, sem interferência alguma nesse processo. A concessão do benefício dependerá do número de famílias atendidas no município em relação à estimativa de famílias pobres feita para essa localidade (BRASIL, 2020). Na última década houve redução dos domicílios beneficiários do PBF, de 15,9\% para 13,7\% (IBGE, 2019b). Atualmente, o PBF atende mais de 13,5 milhões de famílias com cerca de 2,5 bilhões por mês (BRASIL, 2020).

A gestão do programa é descentralizada, na qual União, estados, municípios e Distrito Federal trabalham de forma compartilhada, sendo corresponsáveis por aperfeiçoar, ampliar e fiscalizar a execução do programa. Em nível federal, o Ministério da Cidadania é o responsável pelo Programa, e a Caixa Econômica Federal é o agente que executa os pagamentos. Ademais, o recebimento do benefício implica no cumprimento de condicionalidades relacionadas à saúde e educação, que visam ampliar e garantir os direitos sociais básicos das famílias, sendo responsabilidade do poder público, assegurar a oferta e a qualidade desses serviços (BRASIL, 2020).

Segundo Cabral et al (2014) desde a implementação do PBF houve uma redução importante nos índices de miséria e pobreza do Brasil. Nesse sentido, Soares, Ribas e Osório 
(2010) em seus estudos constataram que o programa teve uma participação de $21 \%$ na queda registrada no índice Gini (indicador que mede a distribuição, concentração e desigualdade econômica do país, o qual varia de 0 - perfeita igualdade; até 1 - máxima concentração e desigualdade) sendo responsável pela diminuição de $12 \%$ na pobreza e de $19 \%$ na extrema pobreza. Entretanto, conforme verificado na PNAD Contínua (2018) até 2015 houve uma tendência de redução desse índice, porém, a partir de 2016 houve uma reversão, quando este aumentou chegando em 2018 a 0,545 (número referente ao Índice Gini do rendimento médio mensal real domiciliar per capita) (IBGE, 2019b).

Considerando seu importante papel de proteção social, revisão recente da literatura apresenta diversos efeitos do PBF na condição de vida dos seus beneficiários. Dentre eles, destaca-se sua boa focalização, aumento dos gastos com alimentos e resultados positivos em relação à participação escolar (frequência, progressão e permanência). No que se refere à saúde, os resultados também foram positivos, evidenciando maior acesso aos serviços de saúde, e no caso do público infantil, melhora no desenvolvimento físico e diminuição da mortalidade (RIBEIRO; SHIKIDA; HILLBRECHT, 2017).

Outro estudo realizado utilizando dados da Pesquisa de Orçamentos Familiares -POF (2008/2009) no qual investigou o efeito do PBF sobre o estado nutricional das crianças e adolescentes beneficiados, verificou que o programa contribuiu para a melhora do estado nutricional dos beneficiados. Os resultados notificados por este estudo apontaram que para as crianças menores de cinco anos de idade, houve redução de chances de excesso de peso nas áreas urbanas e de subnutrição nas áreas rurais. Para as crianças residentes na área urbana, com idade de cinco a dez anos, o programa colaborou para diminuição das ocorrências de sobrepeso e baixa estatura (NETO; BERRIEL, 2017).

Assim, de acordo com Barbosa et al. (2014) o PBF constitui-se um avanço no campo social, porém, possui limitações importantes. O autor supracitado refere que o programa se limita quando não alcança sua universalidade, tampouco consegue atingir a todos que necessitam de proteção social. Outro limitante colocado é em relação às condicionalidades exigidas na área da educação e saúde, quando o programa determina os compromissos que os beneficiários têm que cumprir, mas não garante serviços de qualidade.

Outro ponto a acrescentar é em relação ao mercado de trabalho dos adultos. Pesquisas recentes apontam para algum efeito na redução da jornada de trabalho e na escolha por trabalho informal, o que pode estar associado com o propósito dos indivíduos fazerem com que suas famílias se enquadrem nos critérios estabelecidos pelo programa (RIBEIRO; SHIKIDA; HILLBRECHT, 2017). Nesse seguimento, Zimmermann e Espínola (2015) 
referem que muitas famílias que não atendem os critérios de inclusão estabelecidos pelo PBF estão sendo beneficiadas, e as que realmente necessitam, consequentemente continuam na fila de espera, desprovidas de proteção social. Acrescentam que uma das causas prováveis de erros de inclusão, é a omissão da renda auferida no mercado informal, o que leva a distorções no processo seletivo das famílias.

\subsubsection{Tipos de benefícios do Programa Bolsa Família}

O valor mensal que a família recebe é resultante da soma de vários tipos de benefícios previstos no PBF. Os tipos e quantidades recebidos por cada família dependem de sua composição (número de pessoas, idades, presença de gestantes, etc.) e da renda familiar dos beneficiários (BRASIL, 2020). Assim sendo, os tipos de benefícios concedidos são:

- Benefício Básico: outorgado às famílias que se encontram em situação de extrema pobreza. O valor mensal do auxílio é de $\mathrm{R} \$ 89,00$;

- Benefício Variável: concedido às famílias que se encontram em situação de pobreza ou extrema pobreza e que possuam em sua composição gestante, nutriz, crianças e adolescentes de 0 a 15 anos de idade. O valor do auxílio é de $\mathrm{R} \$ 41,00$, podendo cada família acumular mensalmente até 5 benefícios, chegando a $\mathrm{R} \$$ 205,00;

- Benefício Variável de 0 a 15 anos: outorgado às famílias que possuam em sua composição, crianças e adolescentes de 0 a 15 anos de idade. $\mathrm{O}$ valor mensal do auxílio é de $\mathrm{R} \$ 41,00$;

- Benefício Variável à Gestante: destinado às famílias que possuem em sua composição gestante, podendo ser pagas até nove parcelas conseguintes a contar da data inicial do pagamento do benefício, desde que a gestação tenha sido reconhecida até o nono mês. O valo mensal do auxílio é de $\mathrm{R} \$ 41,00$;

- Benefício Variável Nutriz: concedido às famílias que possuem em sua composição crianças com idade entre 0 e 6 meses de idade, podendo ser pagas até seis parcelas mensais conseguintes a contar da data inicial do pagamento do benefício, desde que a criança tenha sido reconhecida no Cadastro Único até o sexo mês de vida. O valor mensal do auxílio é de $\mathrm{R} \$ 41,00$;

- Benefício Variável Jovem: destinado às famílias que se encontram em situação de pobreza ou extrema pobreza e que possuam em sua composição adolescente entre 
16 e 17 anos de idade. O valor do auxílio mensal é de $\mathrm{R} \$ 48,00$, podendo cada família acumular até dois auxílios.

- Benefício para Superação da Extrema Pobreza: destinado às famílias que se encontram em situação de extrema pobreza, podendo cada uma receber um benefício por mês. O valor mensal do auxílio varia em razão do cálculo realizado a partir da renda per capta da família e do benefício já recebido no PBF.

Vale ressaltar, que as famílias que se encontram em situação de extrema pobreza podem aglomerar o benefício Básico, o Variável e o Variável Jovem, até o máximo de R\$ 372,00 mensal, bem como, acumular também um benefício para Superação da Extrema Pobreza. No mais, o PBF paga no máximo, até R \$ 390,00 por família, tendo os beneficiários autonomia para fazer uso dos recursos recebidos conforme suas necessidades e sem nenhuma interferência externa (BRASIL, 2020).

\subsubsection{Condicionalidades do Programa Bolsa Família}

Para que as famílias possam receber o benefício mensal, estas devem cumprir as condicionalidades estabelecidas pelo Programa Bolsa Família. As Condicionalidades são os compromissos assumidos tanto pelas famílias beneficiárias do Bolsa Família quanto pelo poder público para ampliar o acesso dessas famílias a seus direitos sociais básicos (BRASIL, 2020).

No âmbito da saúde, as famílias beneficiárias assumem o compromisso de manter o cartão de vacinação das crianças menores de sete anos de idade em dia, peso e altura aferidos semestralmente e ter o seu crescimento e desenvolvimento monitorado pela equipe de saúde; As gestantes devem realizar o pré-natal e ir às consultas na Unidade de Saúde. Na educação, os responsáveis têm por obrigação matricular as crianças e os adolescentes de 6 a 17 anos de idade na escola; A frequência escolar mensal das crianças e adolescentes de 6 a 15 anos de idade deve ser no mínimo de $85 \%$ e, para os jovens de 16 e 17 anos de idade de $75 \%$ (BRASIL, 2020).

O registro de acompanhamento das condicionalidades é realizado em sistemas específicos, onde são inseridas informações sobre a agenda da saúde dos beneficiários e a frequência escolar, sendo o monitoramento efetuado individualmente (BRASIL, 2020).

Quando há descumprimento das condicionalidades, são aplicados efeitos gradativos. Inicialmente as famílias recebem uma advertência (não afeta o recebimento do benefício). Se em um período de até seis meses se repete o descumprimento, ocorre o Bloqueio (impede o 
recebimento do benefício por um mês, podendo ser sacado depois caso haja regularização). Caso nesse mesmo período ainda persista o não cumprimento, há a suspensão (benefício suspenso por dois meses, sem possibilidade de reaver essas parcelas) e se não regularizado o cancelamento do direito ao Benefício. Nesse último caso, as famílias só são desligadas do programa após serem acompanhadas pela área da assistência social do município (BRASIL, 2020).

\subsection{Transição Nutricional}

Ao longo do último século, o Brasil passou por importantes modificações estruturais, representadas no aumento da população urbana e expectativa de vida e redução da taxa de fecundidade e de mortalidade infantil, o que caracteriza o conceito de transição demográfica (BATISTA-FILHO; RISSIN, 2003).

Da mesma forma, desde 1980, a transição epidemiológica, assinalada pela diminuição da mortalidade por doenças infecciosas e aumento das doenças crônicas não transmissíveis, vem se manifestando (LAURENTI, 1990). Consequentemente, no mesmo período evidencia-se uma transição no perfil nutricional da população brasileira, a qual se torna mais evidente a cada ano. A desnutrição, antes marcante, sofre contínua diminuição na sua prevalência, ao passo que os índices de incidência de obesidade aumentam ano após ano, caracterizando o processo de transição nutricional. Essa inversão de papeis é uma tendência mundial e se mostra cada vez maior na população mais jovem, principalmente crianças e adolescentes (MONTEIRO; MONDINI; COSTA, 2000).

No Brasil, a transição nutricional começou a ser observada a partir da década de 1970 , quando inquéritos populacionais realizados no país já apresentavam resultados que corroboravam com este fenômeno (IBGE, 1976, 1990, 2006b, 2010). Pesquisas recentes, também a nível nacional, apontam que mais de 50\% da população brasileira apresenta excesso de peso, enquanto 2,5\% está com déficit de peso (IBGE, 2015; BRASIL, 2017).

Por ser um fenômeno que abrange toda população, a transição nutricional não ocorre de forma uniforme. Esta pode surgir em momentos diferentes e com níveis distintos de intensidade, segundo a característica socioeconômica e demográfica da população (SANCHES, 2012).

Nesse sentido, estudo realizado com beneficiários do PBF constatou prevalências menores de excesso de peso e obesidade em relação aos dados nacionais (IBGE, 2010), porém significativas, haja vista que se trata de indivíduos em situação de vulnerabilidade social. 
Destaca-se, que este foi o primeiro estudo realizado com esta população, cujo objetivo foi estimar a prevalência de sobrepeso e obesidade em crianças de cinco a dez anos de idade, no período de 2008 a 2010, na qual se identificou aumento de 7,3\% de sobrepeso tanto para o sexo feminino quanto para o masculino. Já a obesidade, houve aumento de $1,8 \%$ e $7,4 \%$ entre meninas e meninos, respectivamente. (SILVA, 2011).

Pesquisa recente, na qual se avaliou o estado nutricional de crianças maiores de cinco anos e menores de dez anos, beneficiárias do PBF no período de 2011 a 2015, constatou prevalências de excesso de peso de 23,42\% e 35,76\% no Acre e Rio Grande do Sul, respectivamente. Os autores verificaram que durante os anos analisados, o sobrepeso verificado nas crianças dos respectivos estados apresentou tendência crescente (FREITAS et al., 2017).

Segundo pesquisadores, a transição nutricional verificada no Brasil é consequência das transformações nos determinantes sociais ocorridas nas últimas décadas, da industrialização e mecanização da produção, da urbanização acelerada, do aumento na renda, do maior acesso aos alimentos inclusive os processados e das mudanças de hábitos alimentares, muitas vezes não saudáveis (CARDOSO et al., 2017; FREITAS et al., 2017). 


\section{JUSTIFICATIVA}

O PBF tem como objetivo combater a fome, reduzir as desigualdades sociais bem como promover a SAN de seus beneficiários. No entanto, desde sua implementação muitas pesquisas foram realizadas a fim de identificar a condição de (in) segurança alimentar de seus beneficiários. Assim, os resultados apontam para prevalências significantes de IAN entre a população estudada, das quais, chama atenção para os níveis moderada e grave, representadas pela restrição alimentar e/ou fome vivenciadas pelos indivíduos. O que sugere que existe uma lacuna entre os objetivos propostos pelo programa e a realidade dos beneficiários.

Considerando que a IAN pode causar inúmeras consequências, dentre elas, a mortalidade infantil, prejuízo ao desenvolvimento físico e mental, baixo peso ao nascer, mortalidade materna e evasão escolar, e que as principais repercussões relacionadas a esta condição podem ser observadas em indivíduos em situação de vulnerabilidade social, é essencial identificar sua magnitude e fatores ambientais, socioeconômicos e demográficos envolvidos, para possibilitar o norteamento de políticas públicas.

Salienta-se que até o presente momento nenhum estudo avaliou a situação IAN, assim como a situação socioeconômica e demográfica das famílias beneficiárias do Programa Bolsa Família na cidade de Ribeirão Preto. Desta forma, esta pesquisa visa estudar a condição de IAN em famílias incluídas no Programa Bolsa Família, no município de Ribeirão Preto, São Paulo. 


\section{OBJETIVOS}

\subsection{Objetivo Geral}

Avaliar a condição de Insegurança Alimentar e Nutricional de famílias beneficiárias do Programa Bolsa Família, moradoras no Distrito Sanitário Oeste do município de Ribeirão Preto, São Paulo.

\subsection{Objetivos Específicos}

- Descrever as prevalências de Insegurança Alimentar e Nutricional em seus diferentes níveis nas famílias beneficiárias estudadas;

- Caracterizar o perfil socioeconômico e demográfico das famílias estudadas;

- Caracterizar o estado nutricional dos titulares do benefício das famílias estudadas;

- Caracterizar o estado nutricional das crianças com até seis anos, onze meses e vinte e nove dias de idade pertencentes às famílias estudadas. 


\section{CASUÍSTICA E MÉTODOS}

\subsection{Modelo do estudo}

A presente pesquisa caracteriza-se como um estudo descritivo do tipo inquérito, feito de forma transversal, sobre a Insegurança Alimentar e Nutricional de famílias beneficiárias do PBF, residentes no Distrito Sanitário Oeste do município de Ribeirão Preto, São Paulo.

\subsection{Local do Estudo}

O estudo foi realizado no município de Ribeirão Preto, localizado no nordeste do estado de São Paulo, a $330 \mathrm{~km}$ da capital de São Paulo, com população estimada para 2019 de 703.293 habitantes (IBGE, 2019a). No passado, considerada maior produtora mundial de café, recebeu apelido de "Califórnia brasileira", por combinar uma economia fundamentada no agronegócio e alta tecnologia, riqueza e tempo ensolarado ao longo do ano. Atualmente, se destaca como a "Capital do Agronegócio" pela sua magnífica produtividade nesse setor (USP, 2012).

No município de Ribeirão Preto, a assistência à saúde é estruturada em cinco regiões, denominadas Distritos de Saúde. Estes estão localizados nas regiões: Norte - Distrito do Simioni, Sul - Distrito de Vila Virgínia, Leste - Distrito de Castelo Branco, Oeste - Distrito de Sumarezinho e Região Central - Distrito Central (Figura 1).

Figura 1- Distritos de Saúde do município de Ribeirão Preto, São Paulo.

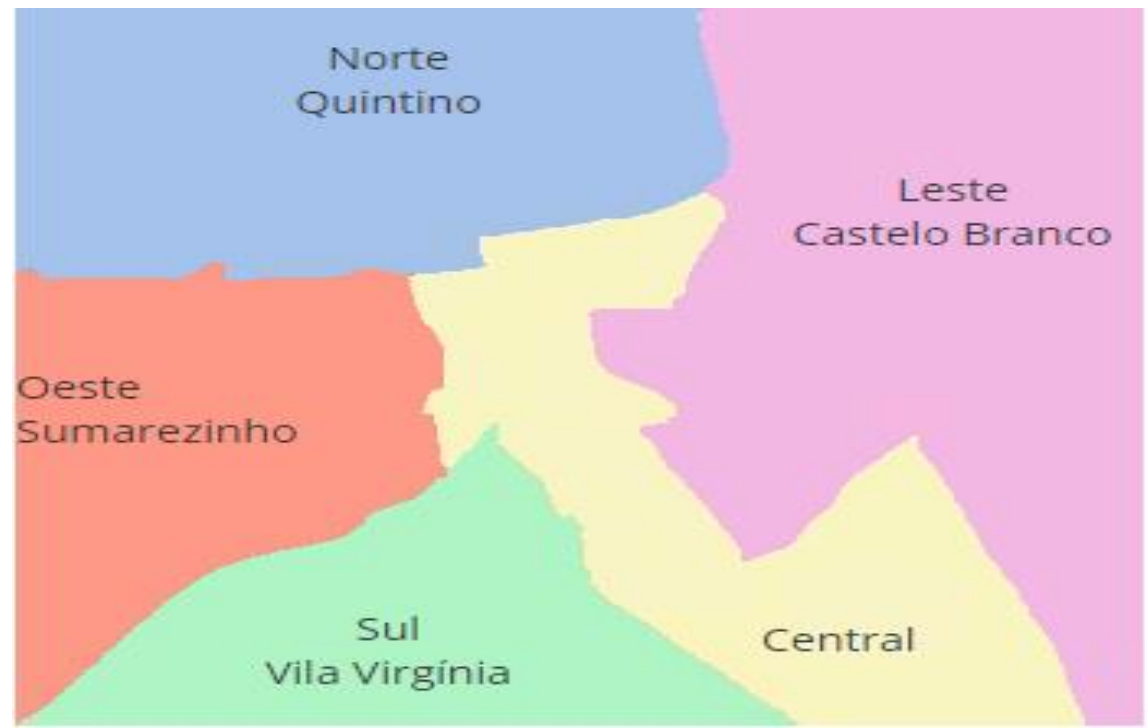

Fonte: Ribeirão Preto, 2020. 
Os Distritos de Saúde são regiões com áreas e populações delimitadas a partir de aspectos geográficos, econômicos e sociais, que reúnem inúmeras Unidades de Saúde e outros equipamentos sociais. Cada Distrito de Saúde conta com 1 Unidade Básica Distrital de Saúde (UBDS) onde são oferecidos serviços ambulatoriais e de especialidades. Ademais, cada Distrito é constituído por várias Unidades Básicas de Saúde (UBS) no modelo tradicional ou com equipes de saúde da família, objetivando prestar atendimento básico nas áreas médicas, odontológicas e de enfermagem para a população residente na sua área de abrangência. A rede básica como um todo é constituída por 02 Centros de Saúde Escola (CSE); 23 Unidades Básicas de Saúde (UBS); 17 Unidades de Saúde da Família (USF); 01 Centro Médico Social Comunitário (CMSC); e 17 Unidades Especializadas (PREFEITURA MUNICIPAL DE RIBEIRÃO PRETO, 2020).

O presente estudo foi realizado no Distrito Sanitário Oeste, que possui aproximadamente 151.218 habitantes e 20 unidades de saúde (PREFEITURA MUNICIPAL DE RIBEIRÃO PRETO, 2011). Segundo dados obtidos na Secretaria Municipal de Saúde de Ribeirão Preto, na última vigência (segundo semestre de 2019) foram acompanhadas neste Distrito 1985 famílias beneficiárias do PBF, distribuídas em 18 Unidades de Saúde.

\subsection{População}

\subsubsection{População de referência}

Famílias beneficiárias do Programa Bolsa Família.

\subsubsection{População de estudo}

Famílias beneficiárias do Programa Bolsa Família residentes no Distrito Sanitário Oeste do município de Ribeirão Preto, São Paulo.

\subsubsection{Critérios de inclusão}

- Residir no Distrito Sanitário Oeste do município de Ribeirão Preto, São Paulo;

- Famílias beneficiárias do Programa Bolsa Família há mais de seis meses;

- Concordância em participação no estudo através da assinatura do Termo de Consentimento Livre e Esclarecido (TCLE).

\subsubsection{Critérios de exclusão}

- Não estar recebendo o benefício no momento da entrevista; 
- Famílias não encontradas após três tentativas;

- Titulares do benefício com déficit cognitivo ou dificuldade de comunicação.

\subsection{Cálculo amostral}

Para a determinação do tamanho amostral, considerou-se a proporção de $22,6 \%$ de insegurança alimentar na população brasileira (IBGE, 2014) com precisão de 5\%, com base na fórmula:

$$
\mathrm{n}=\frac{\mathrm{Z} \alpha^{2} \mathrm{PQ}}{\mathrm{d}^{2}}=\frac{(1,96)^{2} \times 22,6 \times 77,4}{5^{2}}=\frac{3,84 \times 1749,24}{25}=269 \text { famílias }
$$

Onde:

$\mathrm{n} \quad=$ Total da amostra

$\mathrm{Z} \alpha^{2}=1,96$

$\mathrm{P}$ = Prevalência de IA na população brasileira

$\mathrm{Q}=$ Diferença de $\mathrm{P}$

$\mathrm{d}^{2}=$ Precisão

Posteriormente, considerando uma população finita, foi utilizada a fórmula:

$$
\mathrm{nc}=\frac{\mathrm{n}}{1+\frac{\mathrm{n}-1}{\mathrm{~N}}}=\frac{269}{1+\frac{268}{2554}}=\frac{269}{1,105}=244 \text { Famílias }
$$

Onde:

$\mathrm{nc}=\mathrm{n}$ corrigida;

$\mathrm{N}$ = número total de beneficiários do PBF no Distrito Sanitário Oeste na segunda vigência de 2016.

O tamanho mínimo para a amostra foi de 244 famílias, e a amostra final do estudo foi estimada em 269 famílias (considerando 10\% de perdas) o que equivale a 10,5\% da população de beneficiários do distrito oeste no período da realização do cálculo. 


\subsection{Aspectos éticos}

O projeto foi apresentado e aprovado pela Secretaria Municipal de Saúde de Ribeirão Preto e posteriormente aprovado pelo Comitê de Ética em Pesquisa (CEP) do CSE Joel Domingos Machado da Faculdade de Medicina de Ribeirão Preto (Certificado de Apresentação para Apreciação Ética (CAAE) protocolo $n^{\circ} 74053517.1 .0000 .5414$, parecer $n^{\circ}$ 2261509), considerando as recomendações da Comissão Nacional de Ética em Pesquisa (CONEP), conforme Resolução n 466/2012 do Conselho Nacional de Saúde.

Após aprovação do estudo pelo CEP, os gerentes das unidades de saúde sorteadas foram contatados e esclarecidos a respeito da pesquisa e metodologia a ser desenvolvida. A pesquisa iniciou-se somente após consentimento dos gerentes das respectivas Unidades de Saúde.

Os beneficiários sorteados foram esclarecidos e convidados a participar do estudo, sendo necessária a assinatura do TCLE caso concordassem a participar. Se houvesse dificuldade na leitura do TCLE, o documento era lido de forma clara pela pesquisadora, possibilitando a tomada de decisão consciente para participar ou não do estudo.

\subsection{Análise crítica dos riscos/desconfortos e benefícios}

O presente estudo ofereceu riscos/desconfortos mínimos aos participantes, tais como:

- A aplicação do questionário contendo dados socioeconômicos e demográficos e a avaliação da Insegurança Alimentar e Nutricional poderiam causar desconforto/constrangimento ao entrevistado, por se tratar de perguntas relacionadas à suas condições de vida. Para minimizar este desconforto, o entrevistado foi esclarecido que poderia responder em outro momento ou mesmo se recusar a participar do estudo sem qualquer prejuízo para ele ou sua família. A entrevista foi realizada em horário conveniente para o participante e em local reservado para evitar constrangimentos, por abordar assuntos relacionados a renda, disponibilidade e acesso aos alimentos;

- A aferição das medidas antropométricas poderiam oferecer riscos relacionados ao procedimento, isto é, considera-se como risco, a possibilidade de se machucarem ao subir na balança. E neste caso, o procedimento foi realizado cuidadosamente pela pesquisadora, já capacitada para aferição de medidas antropométricas. Para a avaliação antropométrica foram utilizados equipamentos portáteis que reduzem o risco de quedas; 
- A perda dos dados coletados e quebra de sigilo das informações coletadas foi evitada por meio de armazenamento dos dados, sem identificação individual e protegidos por equipamentos com senhas em poder da pesquisadora. As famílias foram identificadas por números e o nome só contava no TCLE.

Como benefício indireto às famílias incluídas no estudo, considerou-se que o diagnóstico do estado nutricional do adulto e das crianças menores de sete anos, bem como a caracterização destas famílias segundo sua condição de IA, poderá auxiliar a equipe de saúde a adotar estratégias eficazes para realidade de saúde encontrada.

\subsection{Estudo Piloto}

Antes de iniciar o trabalho de campo, realizou-se um estudo piloto com oito famílias beneficiárias, selecionados através de amostragem aleatória simples, com intuito de avaliar a adequação dos instrumentos da pesquisa, bem como, identificar problemas e dificuldades operacionais. Ressalta-se, que esses dados não fizeram parte da amostra final da pesquisa.

\subsection{Coleta de dados}

\subsubsection{Seleção dos participantes do estudo}

Para seleção dos participantes da pesquisa, foi solicitado ao responsável pelo PBF, no âmbito da Secretaria Municipal de Assistência Social de Ribeirão Preto, São Paulo, os dados referentes às famílias beneficiárias do programa vinculadas ao Distrito Sanitário Oeste. Deste modo, obteve-se uma listagem com os nomes de todos os titulares que estavam recebendo o benefício na última vigência do programa (segundo semestre de 2017). A seleção foi realizada por amostragem aleatória simples, com o auxílio do programa Sorteador On line, desenvolvido pela Geekster ${ }^{1}$. Simultaneamente, foi solicitado e autorizado o acesso ao Sistema Hygiaweb, para obtenção do contato telefônico e residencial da família, como também sua Unidade Básica de Saúde (UBS) de referência.

O Sistema Hygiaweb é um sistema de gestão em saúde on line, utilizado no município de Ribeirão Preto, São Paulo, que possui como funções a configuração de agendas, agendamento de pacientes, requisição e disponibilização de resultado de exames online, controle e aplicação de vacinas, dispensação de medicamentos, regulação de encaminhamentos,

\footnotetext{
${ }^{1}$ Disponível em https://sorteador.com.br
} 
atendimento ambulatorial online, solicitação de internações de urgência, geração de atestados e declaração de comparecimento e faturamento ambulatorial (RIBEIRÃO PRETO, 2020).

O acesso ao Sistema Hygiaweb foi realizado no Arquivo Central da Secretaria Municipal de Saúde, sob a supervisão e orientação da gerencia desse setor. Após essa etapa, as famílias foram agrupadas de acordo com a UBS de referência, sendo os gerentes dessas unidades contatados para início do trabalho de campo.

\subsubsection{Contato com as famílias selecionadas}

O contato com as famílias foi realizado das seguintes formas:

- Famílias vinculadas às UBS que atuam no modelo de Estratégia de Saúde da família: os Agentes Comunitários de Saúde (ACS) acompanhavam a pesquisadora nas Visitas Domiciliares (VD), onde as famílias eram esclarecidas sobre os objetivos e procedimentos relacionados à pesquisa e convidadas a participar do estudo. Caso aceitassem e assinassem o TCLE, os dados eram coletados em seu domicílio.

- Famílias vinculadas às UBS tradicionais que não contavam com Programa de Agentes Comunitários de Saúde (PACS): o contato com estas famílias era realizado através de telefonemas, onde a pesquisadora em conversa com o titular do benefício, abordava sobre os objetivos e procedimentos da pesquisa e efetuava o convite. Caso aceitasse, o titular era convidado a comparecer na UBS que estava vinculado, em dia e horário determinado, onde havia uma sala reservada para a realização da pesquisa. Nas famílias que havia crianças com até seis anos, onze meses e vinte nove dias de idade era solicitado que também as levassem para a avaliação antropométrica. Na data agendada, aqueles que compareciam na UBS eram novamente esclarecidos sobre os objetivos e procedimentos a serem realizados e, caso concordassem em participar e assinassem o TCLE, eram coletados os seus dados e se fosse o caso, das crianças.

Ressalta-se que as famílias vinculadas às UBS que atuam no modelo de Estratégia de Saúde apresentaram uma melhor adesão ao estudo. Nesse caso, a não participação foi bem inferior quando comparada às famílias vinculadas às UBS tradicionais que não contavam com PACS. Um dos motivos que pode está relacionado é a eficácia da visita domiciliar, sendo esta mais aceita pela população. 


\subsubsection{Período da coleta de dados}

A coleta de dados foi realizada no período de janeiro/2018 a outubro/2018, sendo todos os procedimentos (entrevista/ dados antropométricos) realizados pela pesquisadora. Devido a inúmeras dificuldades para contatar as famílias e a não participação, ao final da pesquisa havia sido selecionadas 575 famílias, destas, apenas obteve-se êxito no contato e participação de 246. Por conseguinte, a presente pesquisa foi realizada com 246 famílias beneficiárias do PBF, residentes no Distrito Sanitário Oeste do Município de Ribeirão Preto, São Paulo.

Como mencionado acima, o contato com as famílias foi um processo árduo, por apresentar alguns percalços, tais como:

- Mudança de endereço e não atualização dos dados cadastrais;

- Por ser em horário comercial a realização da pesquisa, não encontrar o titular em casa, devido ao trabalho;

- Estar com o benefício bloqueado no momento de realização da pesquisa;

- Estar viajando no período da realização da pesquisa;

- Não comparecimento na Unidade de Saúde, em dia e horário agendado;

- Recusar a participar da pesquisa;

\subsubsection{Instrumento utilizado para a coleta de dados}

Elaborou-se um questionário estruturado, aplicado ao titular do benefício sob forma de entrevista, dividido em 5 blocos:

Bloco I: Dados socioeconômicos e demográficos. Composto por quatorze perguntas fechadas, incluindo as seguintes variáveis: relacionadas ao titular do benefício - sexo, data de nascimento, cor, escolaridade, estado civil, ocupação, se recebe outro benefício; renda familiar; gasto médio com alimentação; e caracterização do domicílio - casa própria, alugada ou de familiares, tipo de moradia - alvenaria acabada, inacabada, madeira ou papelão, quantidade de cômodos; abastecimento de água; coleta de lixo; se possui filtro de água e classe econômica. A classificação econômica foi realizada através da aplicação do Critério de Classificação Econômica do Brasil (CCEB) desenvolvido pela Associação Brasileira de Empresas de Pesquisa (ABEP) de 2015 (ABEP, 2016), o qual possui como principal objetivo estimar o poder de compra das pessoas/famílias, distribuindo-as em classes econômicas. A classificação econômica se dá por meio da obtenção de informações relacionadas à posse de determinados "itens de conforto" tais como, banheiros, empregados domésticos, automóveis, 
microcomputador, lava louça, geladeira, freezer, lava roupa, DVD, micro-ondas, motocicleta e secadora de roupa. Para classificação econômica, considera-se a quantidade de itens que o indivíduo/família possui e atribuem pontos de acordo com a presença, ou, no caso de ausência de um determinado item, nada se acrescenta. Agregado a isso, se tem a escolaridade do chefe da família, água encanada e rua pavimentada, que também recebem uma pontuação. A somatória dos pontos obtidos incluirá o indivíduo/família nas classes A, B, C, D ou E.

Bloco II: Conhecimento sobre o PBF. Composto por quatro perguntas fechadas, incluindo as seguintes variáveis: como soube do PBF; utilização do benefício; quem frequenta a unidade de saúde; frequência dos beneficiários à unidade de saúde.

Bloco III: Avaliação da IA. Para caracterizar a situação de IA familiar, foi utilizada a Escala Brasileira de Insegurança Alimentar (BRASIL, 2014) que avalia de maneira direta a percepção e experiência com a fome de uma população.

Bloco IV: Composição Familiar. Foram incluídas as seguintes variáveis: sexo; idade; parentesco; escolaridade; trabalho remunerado; tipo de trabalho.

Bloco V: Dados das crianças. Foram incluídas as seguintes variáveis: sexo; data de nascimento; escolaridade; peso atual e altura atual.

\subsubsection{Escala Brasileira de Insegurança Alimentar}

A IAN tem sido assunto muito discutida na literatura nacional e internacional das áreas de saúde, ciências sociais e nutrição, tendo como foco sua ocorrência nos diferentes grupos populacionais, seus determinantes e suas repercussões (PEDRAZA; GAMA, 2015). Milhares de pessoas no mundo são acometidas pela IAN (SPERANDIO; MORAIS; PRIORE, 2018), sendo esta determinada especialmente pelas desigualdades sociais e pobreza (PEDRAZA; GAMA, 2015).

Dentro desse contexto, por ser um problema de grande relevância social, sendo essencial compreender seus riscos e subsidiar a tomada de decisão, houve uma mobilização para o desenvolvimento de estudos em diversos países, incentivando a elaboração de instrumentos e escalas para avaliação da segurança/insegurança alimentar (FACCHINI et al., 2014), tornando assim possível o seguimento de sua evolução, comparabilidade tempo-espacial e estimação das intervenções (PEDRAZA; GAMA, 2015; BEZERRA; OLINDA; PEDRAZA, 2017).

Para tanto, surge nos Estados Unidos o Indicador Cornell - uma escala de percepção e vivência da fome desenvolvida pela Universidade de Cornell, cujo objetivo era estudar de forma direta o fenômeno da fome (BRASIL, 2014). A partir da bem-sucedida experiência 
americana, vários países, sobretudo os da América Latina e Caribe passaram a desenvolver estudos de validação com base nesse indicador, com o intuito de criar instrumentos capazes de serem aplicados em suas respectivas populações (SPERANDIO; MORAIS; PRIORE, 2018).

Nesse sentido, pesquisadores de instituições distintas do Brasil, com a finalidade de elaborar uma escala que atendesse a realidade do país e fosse capaz de mensurar diretamente a situação de IAN da população, validaram um método denominado Escala Brasileira de Insegurança Alimentar (EBIA) (BRASIL, 2014).

A princípio, para o desenvolvimento da EBIA, o grupo de pesquisadores partiu da escala americana composta por 18 itens e trabalharam com abordagens metodológicas quantitativas e qualitativas, sendo realizado estudo de validação em quatro cidades brasileiras com população urbana e rural de unidades de federação distintas. Como resultado, origina-se a EBIA, escala composta por 15 perguntas, cada qual com quatro opções de frequência, em tudo considerada de fácil compreensão para realidade brasileira (BRASIL, 2014).

Posteriormente, com a finalidade de aperfeiçoar e atualizar a EBIA para a realidade nutricional brasileira, seu conteúdo foi simplificado e, houve a exclusão de itens redundantes, passando a conter 14 questões sobre a situação alimentar vivenciada no domicilio nos últimos 90 dias que antecedem a entrevista, sem alterar de forma alguma sua consistência interna (BRASIL, 2014).

Ao ser comparada aos demais indicadores, se destaca por viabilizar o diagnóstico do indivíduo ou domicílio em situação de SAN ou IAN (SPERANDIO; MORAIS; PRIORE, 2018). Para tanto, ao final da aplicação do questionário é realizada a soma das respostas afirmativas, na qual é atribuída uma pontuação a cada domicílio e, por fim a classificação do domicílio de acordo com os pontos de corte segundo o nível de segurança/insegurança alimentar estabelecidos, como descritos na tabela abaixo:

Tabela 1 - Pontos de corte segundo nível de Segurança/Insegurança Alimentar e Nutricional

\begin{tabular}{ccc}
\hline & $\begin{array}{c}\text { Domicílios com } \\
\text { menores de 18 anos }\end{array}$ & $\begin{array}{c}\text { Domicílios sem } \\
\text { menores de 18 anos }\end{array}$ \\
\hline SA & 0 & 0 \\
IL & $1-5$. & $1-3$. \\
IM & $6-9$. & $4-5$. \\
IG & $10-14$. & $6-8$.
\end{tabular}

* SA: Segurança Alimentar; IL: Insegurança Alimentar Leve; IM: Insegurança Alimentar Moderada; IG: Insegurança Alimentar Grave.

Fonte: Brasil (2014, p. 09). 
Assim, esta escala é composta por questões que identificam desde a angústia perante a incerteza de obter comida regularmente, até a experiência de ficar um dia inteiro sem ter o que comer (FACCHINI et al., 2014). Ademais, ela permite observar que em um mesmo domicílio a IAN atinge de forma distinta adultos e crianças, no qual as crianças possuem vantagens na oferta dos alimentos em detrimento dos adultos. No caso de privação alimentar entre as crianças, denota a gravidade da IAN em nível domiciliar (SANCHES, 2012; PEDRAZA; GAMA, 2015).

A aplicação da EBIA em estudos populacionais a nível nacional foi promovida pelo Ministério de Desenvolvimento e Combate à Fome (MDS), a qual foi integrada às PNADs 2004, 2009 e 2014 e à Pesquisa Nacional de Demografia e Saúde - PNDS, em 2009 (BRASIL, 2014). Também tem sido relevante o número de pesquisas realizadas a nível local que utilizaram este instrumento.

Além de ser de baixo custo, fácil aplicação, fundamentada na experiência vivenciada e percebida pelas famílias (SPERANDIO; MORAIS; PRIORE, 2018), reconhecida como indicador sensível para identificar os domicílios em situação de IAN, a EBIA é essencial para avaliar os efeitos das políticas públicas no país (BEZERRA; OLINDA; PEDRAZA, 2017). No entanto, como outros instrumentos, possui desvantagens por ser um questionário subjetivo, podendo ser um viés de informação, motivo pelo qual pode não ser empregado como critério de inclusão e/ou exclusão em programas referentes à questão da SAN (SANCHES, 2012).

\subsection{Avaliação do estado nutricional de crianças e titulares do benefício}

Para o diagnóstico do estado nutricional das crianças com até seis anos e do titular do benefício, mensurou-se as medidas antropométricas (peso e comprimento/altura) através de equipamentos portáteis, sendo este procedimento realizado no domicílio ou unidade de saúde (na impossibilidade de aferir as medidas antropométricas no domicílio ou no caso de famílias pertencentes a unidades de saúde que não possuem ACS), conforme disponibilidade dos participantes da pesquisa. Tanto no domicílio quanto na unidade de saúde, a coleta de dados do peso e comprimento/altura das crianças, bem como, dos titulares do benefício, foi realizada após entrevista, quer seja no período da manhã ou tarde.

Os procedimentos para coleta dos dados antropométricos foram realizados conforme o protocolo recomendado pelo Sistema de Vigilância Alimentar e Nutricional - SISVAN 
(BRASIL, 2011). Anteriormente ao início de cada coleta, os equipamentos foram testados. A avaliação antropométrica das crianças e dos adultos foram avaliados no domicílio ou nas unidades de saúde. O peso foi mensurado com balança digital portátil W920 da marca Wiso Care ${ }^{\circledR}$, com função tara mamãe e bebê e capacidade máxima de $200 \mathrm{~kg}$, subdividido em $50 \mathrm{~g}$. O equipamento foi colocado em superfície lisa, plana e firme, sendo a medida aferida com a criança ou adulto em pé, posicionado no centro da balança, com o mínimo de roupas possível, descalço, ereto, com os pés juntos e os braços estendidos ao longo do corpo, e sem o uso de acessórios que pudessem interferir na medida. As crianças menores de 12 meses foram pesadas no colo da mãe ou responsável, utilizando a função tara mamãe e bebê do equipamento (recurso que permite zerar o peso da mãe para obter o peso da criança) (BRASIL, 2011).

Para aferir a estatura das crianças acima de 24 meses e dos adultos foi utilizado um estadiômetro da marca ALTUREXATA®, com extensão de 2,13 metros, subdividido em 0,1 $\mathrm{cm}$. O equipamento foi colocado em superfície lisa, plana e firme, na posição vertical. A criança ou adulto foi posicionada no centro do equipamento, de costas, com a postura ereta, descalço, sem uso de adereços na cabeça, com os braços estendidos ao longo do corpo, com a cabeça posicionada no plano Frankfurt, com os pés e calcanhares unidos e encostados na barra de leitura, sendo a leitura realizada em seguida, através da de um cursor com indicação para leitura lateral (parte móvel do equipamento) (BRASIL, 2011).

Para as crianças menores de 24 meses utilizou-se o mesmo equipamento, com um adaptador próprio para medição na posição horizontal. O equipamento foi situado em superfície lisa, plana e firme, sendo a criança acomodada deitada, com a lateral do corpo encostada na régua antropométrica, descalça e com a cabeça sem uso de adereços. Com a ajuda da mãe ou responsável, a cabeça da criança foi posicionada encostada na parte fixa do equipamento, mantendo o rosto reto e o queixo distante do peito no plano de Frankfurt, com os braços estendidos ao longo do corpo, os joelhos pressionados para baixo e pés em ângulo de $90^{\circ}$ para a leitura da medida na parte móvel do equipamento (BRASIL, 2011).

Os índices antropométricos aplicados para avaliação das crianças de zero a cinco anos incompletos de idade foram: Peso para Idade (P/I); Estatura para Idade (E/I); Índice de Massa Corpórea para Idade (IMC/I) e Peso para Estatura (P/E). A avaliação das crianças com idade igual ou superior a cinco anos completos foi realizada com o emprego dos índices antropométricos P/I, IMC/I e E/I. Estes índices preconizados pela Organização Mundial da Saúde (OMS) foram adotados pelo Ministério da Saúde para avaliação da população brasileira 
(OMS 2006, 2007; BRASIL, 2011). Para o cálculo dos índices antropométricos foram utilizados os dados de peso (atual), altura (atual), idade e sexo.

O cálculo do estado nutricional das crianças de zero a sessenta meses foi realizado no programa Anthro® da OMS. Já para o cálculo das crianças acima de sessenta meses utilizouse o programa AnthroPlus ${ }^{\circledR}$. Posteriormente, no programa Epi Info® classificou-se o estado nutricional das crianças, utilizando os pontos de cortes recomendados pelo SISVAN do Ministério da Saúde, descritos no quadro abaixo.

Quadro 1 - Classificação do estado nutricional das crianças segundo os índices antropométricos.

\begin{tabular}{|c|c|c|c|c|c|c|c|c|}
\hline \multirow{3}{*}{\multicolumn{2}{|c|}{ VALORES CRÍTICOS }} & \multicolumn{7}{|c|}{ INDICES ANTROPOMÉTRICOS } \\
\hline & & \multicolumn{4}{|c|}{ CRIANÇAS DE 0 A 5 ANOS INCOMPLETOS } & \multicolumn{3}{|c|}{$\begin{array}{l}\text { CRIANCCAS DE } 5 \text { A } 10 \text { ANOS } \\
\text { INCOMPLETOS }\end{array}$} \\
\hline & & $\begin{array}{l}\text { Peso para } \\
\text { idade }\end{array}$ & $\begin{array}{l}\text { Peso para } \\
\text { estatura }\end{array}$ & $\begin{array}{l}\text { IMC para } \\
\text { idade }\end{array}$ & $\begin{array}{c}\text { Estatura } \\
\text { para } \\
\text { idade }\end{array}$ & $\begin{array}{l}\text { Peso para } \\
\text { idade }\end{array}$ & $\begin{array}{l}\text { IMC para } \\
\text { idade }\end{array}$ & $\begin{array}{c}\text { Estatura } \\
\text { para } \\
\text { idade }\end{array}$ \\
\hline $\begin{array}{c}<\text { Percentil } \\
0,1\end{array}$ & $\begin{array}{c}<\text { Escore-2 } \\
-3\end{array}$ & $\begin{array}{c}\text { Muito } \\
\text { baixo peso } \\
\text { para a } \\
\text { idade }\end{array}$ & $\begin{array}{l}\text { Magreza } \\
\text { acentuada }\end{array}$ & $\begin{array}{c}\text { Magreza } \\
\text { acentuada }\end{array}$ & $\begin{array}{c}\text { Muito } \\
\text { baixa } \\
\text { estatura } \\
\text { para a } \\
\text { idade }\end{array}$ & $\begin{array}{c}\text { Muito } \\
\text { baixo peso } \\
\text { para a } \\
\text { idade }\end{array}$ & $\begin{array}{l}\text { Magreza } \\
\text { acentuada }\end{array}$ & $\begin{array}{c}\text { Muito } \\
\text { baixa } \\
\text { estatura } \\
\text { para a } \\
\text { idade }\end{array}$ \\
\hline $\begin{array}{c}\geq \text { Percentil } \\
0,1 \text { e }< \\
\text { Percentil } 3\end{array}$ & $\begin{array}{c}\geq \text { Escore-z } \\
-3 \mathrm{e}< \\
\text { Escore-z }-2\end{array}$ & $\begin{array}{l}\text { Baixo } \\
\text { peso para } \\
\text { a idade }\end{array}$ & Magreza & Magreza & $\begin{array}{c}\text { Baixa } \\
\text { estatura } \\
\text { para a } \\
\text { idade }\end{array}$ & $\begin{array}{c}\text { Baixo peso } \\
\text { para a } \\
\text { idade }\end{array}$ & Magreza & $\begin{array}{c}\text { Baixa } \\
\text { estatura } \\
\text { para a } \\
\text { idade }\end{array}$ \\
\hline $\begin{array}{c}\geq \text { Percentil } \\
3 \mathrm{e}< \\
\text { Percentil } \\
15\end{array}$ & $\begin{array}{c}\geq \text { Escore-z } \\
-2 \mathrm{e}< \\
\text { Escore-z }-1\end{array}$ & \multirow{3}{*}{$\begin{array}{c}\text { Peso } \\
\text { adequado } \\
\text { para a } \\
\text { idade }\end{array}$} & \multirow{2}{*}{ Eutrofia } & \multirow{2}{*}{ Eutrofia } & \multirow{5}{*}{$\begin{array}{c}\text { Estatura } \\
\text { adequada } \\
\text { para a } \\
\text { idade }^{2}\end{array}$} & \multirow{3}{*}{$\begin{array}{c}\text { Peso } \\
\text { adequado } \\
\text { para a } \\
\text { idade }\end{array}$} & \multirow{2}{*}{ Eutrofia } & \multirow{5}{*}{$\begin{array}{c}\text { Estatura } \\
\text { adequada } \\
\text { para a } \\
\text { idade }^{2}\end{array}$} \\
\hline $\begin{array}{c}\geq \text { Percentil } \\
15 \text { e } \leq \\
\text { Percentil } \\
85\end{array}$ & $\begin{array}{c}\geq \text { Escore-z } \\
-1 \text { e } \leq \\
\text { Escore-z }+1\end{array}$ & & & & & & & \\
\hline $\begin{array}{c}>\text { Percentil } \\
85 \text { e } \leq \\
\text { Percentil } \\
97\end{array}$ & $\begin{array}{c}>\text { Escore-z } \\
\quad+1 \text { e } \leq \\
\text { Escore-z }+2\end{array}$ & & $\begin{array}{l}\text { Risco de } \\
\text { sobrepeso }\end{array}$ & $\begin{array}{l}\text { Risco de } \\
\text { sobrepeso }\end{array}$ & & & Sobrepeso & \\
\hline $\begin{array}{c}>\text { Percentil } \\
97 \text { e } \leq \\
\text { Percentil } \\
99,9\end{array}$ & $\begin{array}{c}>\text { Escore-z } \\
+2 \mathrm{e} \leq \\
\text { Escore-z+3 }\end{array}$ & \multirow{2}{*}{$\begin{array}{c}\text { Peso } \\
\text { elevado } \\
\text { para a } \\
\text { idade }^{1}\end{array}$} & Sobrepeso & Sobrepeso & & \multirow{2}{*}{$\begin{array}{c}\text { Peso } \\
\text { elevado } \\
\text { para a } \\
\text { idade }^{1}\end{array}$} & Obesidade & \\
\hline $\begin{array}{c}>\text { Percentil } \\
99,9\end{array}$ & $\begin{array}{c}>\text { Escore-z } \\
+3\end{array}$ & & Obesidade & Obesidade & & & $\begin{array}{c}\text { Obesidade } \\
\text { grave }\end{array}$ & \\
\hline
\end{tabular}

Fonte: Adaptado de Organización Mundial de la Salud. Curso de Capacitación sobre la evaluación del crecimiento del niño. Versión 1 - Noviembre 2006. Ginebra, OMS, 2006.

Fonte: Brasil (2008, p. 13).

Para o diagnóstico nutricional dos adultos, utilizou-se a classificação do Índice de Massa Corporal (IMC) proposta pela OMS e adotada pelo Ministério da Saúde. Os pontos de corte estabelecidos para adultos são: Baixo Peso (IMC $<18,5 \mathrm{~kg} / \mathrm{m}^{2}$ ); Eutrofia $(\mathrm{IMC} \geq 18,5$ e IMC $<25 \mathrm{~kg} / \mathrm{m}^{2}$ ); Sobrepeso (IMC $\geq 25$ e $\mathrm{IMC}<30 \mathrm{~kg} / \mathrm{m}^{2}$ ) e Obesidade (IMC $\geq 30 \mathrm{~kg} / \mathrm{m}^{2}$ ) (BRASIL, 2011). 


\subsection{Processamento dos dados e Análise estatística}

Os questionários aplicados foram revistos, codificados e inseridos em banco de dados específico em programa Excel®. A digitação foi realizada em duplicata pela pesquisadora, para conferência da consistência dos dados.

Inicialmente os dados foram categorizados segundo as características socioeconômicas demográficas e de saúde da população por meio de frequências relativas e absolutas. Para essa pesquisa, a condição de (in)segurança alimentar e nutricional da população foi categorizada em dois grupos: grupo de SAN composto pelas famílias identificadas pela EBIA em situação de segurança alimentar mais aquelas em situação de insegurança alimentar leve. O grupo nomeado de IAN foi formado pelas famílias identificadas como em situação de insegurança alimentar moderada mais aquelas identificadas como em condição de insegurança alimentar grave.

Para estimar as razões de prevalência (RP) dos grupos (SAN e IAN) de acordo com as variáveis de interesse foi utilizado o modelo de regressão log-binomial simples e múltiplo (SKOV et al., 1998), dado que a resposta era binária (Insegurança = Sim ou Não).

Todas as análises foram feitas através do software SAS 9.2. Para todas as comparações adotou-se um nível de significância de 5\%.

\subsection{Limitações do estudo}

Por se tratar de assuntos que envolvem questões relacionadas à renda e acesso a alimentos, os participantes podem ter omitido e/ou falsificado (no caso de beneficiários que trabalhavam no momento da coleta de dados e não estariam dentro dos critérios de inclusão estabelecidos no programa) as informações. 


\section{RESULTADOS}

\subsection{Insegurança Alimentar e Nutricional}

Das 246 famílias beneficiárias do PBF avaliadas, observou-se que a maioria (94,3\%) encontrava-se em situação de IA, sendo a graduação desta apresentada na Tabela 2.

Tabela 2 - Caracterização da Insegurança Alimentar das famílias beneficiárias do Programa Bolsa Família no Distrito Sanitário Oeste do município de Ribeirão Preto. Ribeirão Preto, SP 2020.

\begin{tabular}{lcc}
\hline Variável & $\mathbf{n}$ & $\boldsymbol{\%}$ \\
\hline Segurança Alimentar e Nutricional & 14 & 5,7 \\
Insegurança Alimentar & 232 & 94,3 \\
$\quad$ Leve & 101 & 41,1 \\
Moderada & 68 & 27,6 \\
Grave & 63 & 25,6 \\
\hline
\end{tabular}

Fonte: Autoria própria

\subsection{Caracterização socioeconômica e demográfica}

Nas Tabelas 3 e 4 estão descritos os dados relacionados às características dos titulares do benefício e das variáveis socioeconômicas e demográficas das famílias.

A média de idade dos titulares foi de 36,59 anos de idade. Observa-se na Tabela 3 que mais de $90 \%$ dos titulares eram mulheres, com predomínio (54,9\%) de cor/raça parda e escolaridade entre analfabeto a fundamental I completo (53,3\%). Cerca de 52\% tinham companheiro (a) e 64,6\% estavam em situação de desemprego. Segundo o IMC, mais de 70\% da população apresentava excesso de peso (sobrepeso/obesidade). 
Tabela 3 - Características dos titulares do Programa Bolsa Família residentes no Distrito Sanitário Oeste do município de Ribeirão Preto. Ribeirão Preto, SP, 2020.

\begin{tabular}{lcc}
\hline Variável & $\mathbf{n = 2 4 6}$ & $\mathbf{\%}$ \\
\hline Sexo & & \\
Feminino & 240 & 97,6 \\
Masculino & 06 & 2,4
\end{tabular}

\section{Cor/Raça}

Branca/ Amarela

$63 \quad 25,6$

Parda

$135 \quad 54,9$

Preta

48

19,5

\section{Escolaridade}

Analfabeto a Fundamental I completo

$131 \quad 53,3$

Fundamental II a Médio completo

$115 \quad 46,7$

\section{Estado civil}

Com companheiro (a) $128 \quad 52,0$

Sem companheiro (a)

$118 \quad 48,0$

\section{Ocupação}

Ativo

$87 \quad 35,4$

Não ativo

$159 \quad 64,6$

\section{Estado nutricional}

$\begin{array}{lll}\text { Baixo Peso } & 08 & 3,2 \\ \text { Eutrofia } & 57 & 23,2 \\ \text { Sobrepeso } & 86 & 35,0 \\ \text { Obesidade } & 95 & 38,6\end{array}$


Na Tabela 4 observa-se que mais de $60 \%$ dos domicílios tinham até quatro moradores e, $57,7 \%$ das famílias tinham crianças com até sete anos de idade completos. Em relação às condições socioeconômicas, mais da metade (54\%) foram classificados nas classes B2, C1 e C2, 95\% referiram ter renda familiar menor ou igual a dois salários mínimos, e o gasto mensal com alimentação relatado pela maioria (62\%) era menor ou igual a $\mathrm{R} \$ 400,00$.

As moradias em sua maioria (93,5\%) eram constituídas de alvenaria acabada e 73,2 \% possuíam 4 ou mais cômodos. Todos os domicílios estavam ligados à rede pública de abastecimento de água (Daerp), 82,5\% possuíam filtro de água e apenas $0,4 \%$ não eram atendidos pelo serviço de coleta de lixo municipal.

Tabela 4 - Caracterização socioeconômica e demográfica das famílias beneficiárias do Programa Bolsa Família residentes no Distrito Sanitário Oeste do município de Ribeirão Preto. Ribeirão Preto, SP, 2020.

\begin{tabular}{lcc}
\hline Variável & $\mathbf{n = 2 4 6}$ & $\mathbf{\%}$ \\
\hline Número de moradores & 151 & 61,4 \\
Até 4 & 95 & 38,6
\end{tabular}

\section{Crianças até 7 anos completos}

Sim

\section{Nível socioeconômico**}

$\mathrm{B} 2 / \mathrm{C} 1 / \mathrm{C} 2$

$\mathrm{D} / \mathrm{E}$

\section{Renda familiar}

$\leq 1$ salário mínimo

$115 \quad 47,0$

$>1$ Salário mínimo e $\leq 2$ salários mínimos

$118 \quad 48,0$

$>2$ salários mínimos

$11 \quad 5,0$


(conclusão)

\begin{tabular}{lcc}
\hline Variável & $\mathbf{n = 2 4 6}$ & \% \\
\hline Gasto com a alimentação $(\mathbf{R} \$)$ & & \\
$\leq 300,00$ & 60 & 25,0 \\
$>300,00 \mathrm{a} \leq 400,00$ & 89 & 37,0 \\
$>400,00$ & 92 & 38
\end{tabular}

Tipo de moradia

Casa/Apartamento próprio

$154 \quad 62,6$

Casa/Apartamento alugado

$31 \quad 12,6$

Outra

$61 \quad 24,8$

Tipo de construção da moradia

Alvenaria acabada $230 \quad 93,5$

Alvenaria inacabada

$14 \quad 5,7$

Madeira

$02 \quad 0,8$

\section{Número de cômodos}

Até 3

$66 \quad 26,8$

4 ou mais

$180 \quad 73,2$

Abastecimento de água

Sim

246

100

Filtro de água

Sim

203

82,5

Não

43

17,5

Coleta de lixo

Sim

$245 \quad 99,6$

Não

$01 \quad 0,4$

Fonte: Autoria própria

** Conforme o "Critério de Classificação Econômica Brasil 2016" - Associação Brasileira de Empresas de Pesquisa (ABEP). 


\subsection{Bolsa Família e recebimento de outros benefícios}

$\mathrm{Na}$ Tabela 5 observa-se que mais de $60 \%$ dos participantes da pesquisa tiveram conhecimento sobre o PBF através do famoso "boca a boca", bem como outros meios de comunicação formais. A maioria $(60,4 \%)$ recebia o benefício há mais de quatro anos, sendo que, $74,3 \%$ recebiam um valor mensal de $\mathrm{R} \$ 200,00$ ou menos, e 70,7\% aplicavam o recurso para a compra de alimentos.

$\mathrm{O}$ cadastro e recebimento do BF não impede que as famílias contempladas recebam simultaneamente outros benefícios, seja de alimentos ou recursos financeiros, desde que, este último associado à renda familiar e dividido entre os membros não ultrapasse os critérios de renda per capita definidos no programa. Deste modo, no presente estudo, 26,8\% das famílias referiram receber outro benefício concomitante ao BF. Cabe destacar, que em alguns casos, as famílias tinham apenas um destes e em outros, os dois. Desta forma, apurou-se que 34,8\% recebem cesta básica (proveniente de familiares e assistente social); 63,6\% Leite (governo); e, $16,7 \%$ recursos financeiros (pensão alimentícia para filhos de pais separados).

Tabela 5 - Informações referentes ao benefício do Programa Bolsa Família relatadas pelas famílias estudadas. Ribeirão Preto, SP, 2020.

\begin{tabular}{lcc}
\hline Variável & $\mathbf{n = 2 4 6}$ & \% \\
\hline Como soube do PBF & 103 & 42,7 \\
Amigos / Familiares & 50 & 20,8 \\
TV / Rádio / Informativo / Internet & 88 & 36,5
\end{tabular}

\section{Tempo de benefício}

06 a 48 meses $\quad 97 \quad 39,6$

49 meses ou mais $\quad 148 \quad 60,4$

\section{Valor do benefício $(\mathbf{R} \$)$}

Entre 39 e 100

Entre 101 e 200

Entre 201 ou mais

$63 \quad 25,7$


(conclusão)

\begin{tabular}{lcc}
\hline Variável & $\mathbf{n = 2 4 6}$ & $\mathbf{\%}$ \\
\hline Utilidade do benefício & 174 & 70,7 \\
Comprar alimentos & 09 & 3,7 \\
Comprar materiais escolares & 39 & 15,8 \\
Comprar roupas & 24 & 9,8 \\
\hline
\end{tabular}

Fonte: Autoria própria

\subsection{Estado nutricional das crianças}

Todas as crianças $(n=206)$ com idade até seis anos, onze meses e vinte nove dias, das famílias beneficiárias foram incluídas no estudo. Verificou-se predomínio do sexo masculino $(52,4 \%)$ e média de idade de 45 meses, com maior proporção de crianças na faixa etária entre 36 e 84 meses.

O estado nutricional das crianças (Tabela 6) foi avaliado através dos indicadores E/I, P/I, P/E e IMC/I. Observou-se que a mais de $90 \%$ das crianças apresentavam peso e estatura adequados para a idade.

Em relação ao indicador P/E, a maioria $(73,4 \%)$ era eutrófica, porém, observou se o risco de sobrepeso em 16,5\% ( $\mathrm{n}=23)$ e o excesso de peso (sobrepeso/obesidade) em 7,9\% $(\mathrm{n}=11)$. Segundo o indicador IMC/I, a maior parte das crianças estudadas estava eutrófica, todavia, o excesso de peso estava presente em $25,5 \%(n=52)$ 
Tabela 6 - Caracterização do estado nutricional das crianças menores de sete anos de idade pertencentes às famílias beneficiárias do Programa Bolsa Família residentes no Distrito Oeste do Município de Ribeirão Preto. Ribeirão Preto, SP, 2020.

\begin{tabular}{|c|c|c|}
\hline Variável & $n=206$ & $\%$ \\
\hline \multicolumn{3}{|l|}{ Estatura para Idade } \\
\hline Baixa estatura para idade & 08 & 3,9 \\
\hline Estatura adequada para idade & 197 & 96,1 \\
\hline \multicolumn{3}{|l|}{ Peso por Idade } \\
\hline Baixo peso por idade & 03 & 1,5 \\
\hline Peso adequado para idade & 188 & 91,7 \\
\hline Peso elevado para idade & 14 & 6,8 \\
\hline \multicolumn{3}{|l|}{ Peso por Estatura } \\
\hline Magreza & 03 & 2,2 \\
\hline Eutrofia & 102 & 73,4 \\
\hline Risco de sobrepeso & 23 & 16,5 \\
\hline Sobrepeso / Obesidade & 11 & 7,9 \\
\hline \multicolumn{3}{|c|}{ Índice de Massa Corporal por Idade } \\
\hline Magreza & 06 & 2,9 \\
\hline Eutrofia & 146 & 71,6 \\
\hline Sobrepeso & 34 & 16,7 \\
\hline Obesidade & 18 & 8,8 \\
\hline
\end{tabular}

Fonte: Autoria própria

$\mathrm{Na}$ Tabela 7 observa-se a prevalência de IAN entre as categorias das variáveis independentes, bem como, as razões de prevalências brutas (IC 95\%) e razões de prevalências ajustadas (IC 95\%) entre o desfecho e as variáveis independentes. Nota-se que as diferenças não foram estatisticamente significantes $(\mathrm{p}<0,05) . \quad$ (Tabela 6). 
Tabela 7 - Prevalência e Razão de Prevalência (RP) bruta e ajustada por regressão logbinomial de Insegurança Alimentar e Nutricional, segundo características socioeconômicas, demográficas e informações relacionadas às famílias beneficiárias do Programa Bolsa Família, residentes no Distrito Sanitário Oeste do município de Ribeirão Preto. Ribeirão Preto, SP, 2020.

\begin{tabular}{|c|c|c|c|c|c|}
\hline Variável & $\begin{array}{l}\text { Insegurança } \\
\text { alimentar } \\
(\mathbf{n}=131)\end{array}$ & $\begin{array}{l}\text { RP Bruta } \\
\text { (IC 95\%) }\end{array}$ & Valor-p & $\begin{array}{l}\text { RP Ajustada } \\
\text { (IC 95\%) }\end{array}$ & Valor-p \\
\hline \multicolumn{6}{|l|}{ Número de moradores } \\
\hline Até 4 & $83(54,97 \%)$ & $1,09(0,85-1,39)$ & 0,50 & $1,16(0,87-1,55)$ & 0,30 \\
\hline Acima de 4 & $48(50,5 \%)$ & & & & \\
\hline \multicolumn{6}{|l|}{ Crianças de até 6 anos } \\
\hline Não & $53(51,0 \%)$ & $0,93(0,73-1,18)$ & 0,54 & $0,82(0,64-1,06)$ & 0,13 \\
\hline Sim & $78(54,9 \%)$ & & & & \\
\hline \multicolumn{6}{|l|}{ Estado Nutricional Titular } \\
\hline Baixo peso/eutrofia & $30(46,1 \%)$ & $0,83(0,62-1,11)$ & 0,20 & $0,79(0,59-1,07)$ & 0,12 \\
\hline Sobrepeso/obeso & $101(55,8 \%)$ & & & & \\
\hline \multicolumn{6}{|l|}{ Grau de instrução } \\
\hline Analfabeto a Fundamental I completo & $75(57,3 \%)$ & $1,18(0,93-1,49)$ & 0,18 & $1,11(0,86-1,42)$ & 0,42 \\
\hline Fundamental II completo/Médio & $56(48,7 \%)$ & & & & \\
\hline \multicolumn{6}{|l|}{ Estado civil } \\
\hline Com companheiro (a) & $67(52,3 \%)$ & $0,97(0,76-1,22)$ & 0,77 & $0,96(0,77-1,19)$ & 0,70 \\
\hline Sem companheiro (a) & $64(54,2 \%)$ & & & & \\
\hline \multicolumn{6}{|l|}{ Gasto com alimentação } \\
\hline$<\mathrm{R} \$ 300,00$ & $30(50,0 \%)$ & $0,87(0,64-1,19)$ & 0.39 & $0,9(0,65-1,25)$ & 0,53 \\
\hline $\mathrm{R} \$ 300,00$ a 400,00 & $51(57,3 \%)$ & $0,96(0,70-1,32)$ & 0.79 & $0,98(0,7-1,36)$ & 0,89 \\
\hline$>\mathrm{R} \$ 400,00$ & $48(52,2 \%)$ & $1,10(0,84-1,43)$ & 0.49 & $1,08(0,84-1,41)$ & 0,54 \\
\hline \multicolumn{6}{|l|}{ Classe econômica } \\
\hline $\mathrm{B} 2 / \mathrm{C} 1 / \mathrm{C} 2$ & $68(51,1 \%)$ & $0,92(0,73-1,16)$ & 0,47 & $0,91(0,71-1,16)$ & 0,45 \\
\hline $\mathrm{D} / \mathrm{E}$ & $63(55,7 \%)$ & & & & \\
\hline \multicolumn{6}{|l|}{ Quant. cômodos casa } \\
\hline Até 3 & $32(48,5 \%)$ & $0,88(0,67-1,17)$ & 0,38 & $0,92(0,67-1,27)$ & 0,62 \\
\hline 4 ou mais & $99(55,0 \%)$ & & & & \\
\hline
\end{tabular}


(conclusão)

\begin{tabular}{|c|c|c|c|c|c|}
\hline Variável & $\begin{array}{c}\text { Insegurança } \\
\text { alimentar } \\
(n=131)\end{array}$ & $\begin{array}{l}\text { RP Bruta } \\
\text { (IC 95\%) }\end{array}$ & Valor-p & $\begin{array}{c}\text { Razão de } \\
\text { prevalência } \\
\text { (IC 95\%) }\end{array}$ & $\begin{array}{c}\text { Valor- } \\
\text { p }\end{array}$ \\
\hline \multicolumn{6}{|l|}{ Possui filtro de água } \\
\hline Não & $112(55,2 \%)$ & $1,25(0,87-1,79)$ & 0,22 & $1,18(0,85-1,63)$ & 0,31 \\
\hline Sim & $19(44,2 \%)$ & & & & \\
\hline \multicolumn{6}{|l|}{ Moradia } \\
\hline Casa/apto alugado/outra & $45(48,9 \%)$ & $0,88(0,68-1,13)$ & 0,30 & $0,85(0,63-1,13)$ & 0,26 \\
\hline Casa/apto próprio & $86(55,8 \%)$ & & & & \\
\hline \multicolumn{6}{|l|}{ Tempo de benefício } \\
\hline 6 a 48 meses & $50(51,6 \%)$ & $0,95(0,75-1,22)$ & 0,70 & $1,04(0,81-1,33)$ & 0,79 \\
\hline 49 meses ou mais & $80(54,1 \%)$ & & & & \\
\hline \multicolumn{6}{|l|}{ Valor Benefício $(R \$)$} \\
\hline Entre 39,00 e 100,00 & $40(51,95 \%)$ & $1,07(0,80-1,43)$ & 0,65 & $1,12(0,83-1,5)$ & 0,47 \\
\hline Entre 101,00 e 200,00 & $51(48,57 \%)$ & $0,84(0,63-1,12)$ & 0,23 & $0,97(0,69-1,36)$ & 0,86 \\
\hline 201,00 ou mais & $39(61,9 \%)$ & $0,78(0,59-1,03)$ & 0,08 & $0,87(0,66-1,15)$ & 0,32 \\
\hline \multicolumn{6}{|l|}{ Outro benefício } \\
\hline Não & $99(55 \%)$ & $\begin{array}{c}1,13(0,86- \\
1,50)\end{array}$ & 0,38 & $1,2(0,93-1,56)$ & 0,15 \\
\hline Sim & $32(48,5 \%)$ & & & & \\
\hline
\end{tabular}




\section{DISCUSSÃO}

A população estudada apresentou elevada prevalência de IAN, na qual a soma da condição moderada e grave corresponde à maioria. No que se refere ao estado nutricional, o excesso de peso foi uma condição prevalente nos titulares, sendo observado também entre as crianças avaliadas, porém, em menor proporção.

\subsection{Insegurança Alimentar e Nutricional}

Os resultados encontrados no presente estudo indicam maior prevalência de IAN em relação aos dados nacionais. Cabe destacar que as pesquisas de base populacional mais recentes (PNAD, 2009 e 2013) quantificaram a IAN da população como um todo, sem analisar separadamente os beneficiários do PBF.

Da mesma forma, quando se avaliou separadamente os beneficiários e não beneficiários de programas de transferência de renda, a primeira pesquisa com representatividade nacional, a PNAD de 2004, revelou que a prevalência de IAN encontrada entre os beneficiários quase que é o dobro (66\%) quando comparada ao outro grupo (IBGE, 2006a), porém, com taxa inferior à presente pesquisa.

Um inquérito de base populacional, realizado com beneficiários do PBF das diferentes regiões do país, evidenciou prevalência geral de IAN de $83,1 \%$, no qual $54,8 \%$ dos beneficiários sofriam de restrição na quantidade de alimentos disponíveis ou passavam fome, isto é, encontravam-se em situação de IAN moderada ou grave (IBASE 2008).

$\mathrm{Na}$ literatura encontrada, o estudo com prevalência mais próxima a presente pesquisa foi conduzido por Bezerra e Pedraza (2015) no qual, ao avaliarem a situação de IAN de famílias com crianças menores de cinco anos residentes em área de vulnerabilidade social de Campina Grande (PB), observaram condição de IAN em $96,1 \%$ da população, destas 34,2\% apresentavam IAN moderada e $32,4 \%$ IAN grave.

Outros estudos realizados em municípios brasileiros, com beneficiários do PBF, também relataram altas prevalências de IAN entre a população estudada, porém, menores que as encontradas no presente estudo. Sperandio e Priore (2015) observaram em Viçosa (MG) 72,8\%. Em Colombo (PR), Monteiro et al. (2014) descrevem prevalência de 81,6\% e Pacheco et al. (2018) em Porto Alegre (RS) de 89,1\%. 
Sanches (2012), em um estudo sobre Segurança Alimentar de famílias com crianças menores de cinco anos que frequentavam Centros de Educação Infantil Municipais (creches) nos cinco distritos de saúde (Norte, Sul, Leste, Oeste e Central) do município de Ribeirão Preto (SP), descreve que 54,4\% das famílias estudadas estavam em situação de IAN. Quando analisado por distritos, relatou que entre eles, o Distrito Oeste apresentava as maiores prevalências $(60,7 \%)$. Ressalta-se, que na pesquisa supracitada, não foi realizada distinção entre famílias beneficiárias do PBF ou não, o que pode explicar a menor porcentagem quando comparada ao presente estudo.

Por outro lado, prevalências de IAN superiores à encontrada no presente estudo, envolvendo beneficiários do PBF, foram constatadas em Araraquara (SP) e Montes Claros (MG), onde foram verificadas prevalências de IAN em 95\% e 100\% das famílias estudadas, respectivamente (TRALDI; ALMEIDA; FERRANTE, 2012; MONTEIRO, SOUZA; PINHO, 2014). Esses achados, assim como os do presente estudo, sugerem a alta vulnerabilidade apresentada pelas famílias beneficiárias do PBF.

Nesse sentido, Ferreira et al (2014) em estudo realizado no Norte de Alagoas, observaram que as famílias beneficiárias do PBF, em comparação com as não beneficiárias, apresentavam maior prevalência de IAN. A suposição levantada pelos autores para explicar tal observação, remete a duas interpretações, das quais, a primeira refere-se à correta focalização do Programa em relação ao processo seletivo dos beneficiários, evidenciando seu alcance às pessoas em situação de maior vulnerabilidade social, ou sob outra perspectiva, sugere a incapacidade do PBF em garantir a SAN das famílias.

Assim, diversos estudos têm corroborado com as interpretações acima citadas, evidenciando como exposto anteriormente, que as famílias beneficiárias de programas de transferência de renda quando analisadas, apresentavam altas prevalências de IAN, o que sugere o destino adequado dos recursos (IBASE, 2008; TRALDI; ALMEIDA; FERRANTE, 2012; MONTEIRO et al.2014; MONTEIRO; SOUZA; PINHO, 2014; SPERANDIO; PRIORE, 2015; PACHECO et al., 2018; SUZART; FERREIRA, 2018;).

Por outro lado, apesar das pesquisas constatarem que o PBF está sendo bem focalizado, é consenso que somente os programas de transferência de renda, não serão capazes de superar a pobreza, desigualdade social e IAN (COTTA; MACHADO, 2013; BEZERRA; OLINDA; PEDRAZA, 2017; SUZARTT; FERREIRA, 2018). Haja vista que a pobreza e desigualdade social persistem há anos no país e creditar que, somente um programa social irá superar essas 
iniquidades, evidencia uma visão ingênua acerca do problema (FERREIRA; MAGALHÃES, 2017).

Nesse contexto, de acordo com Monteiro et al. (2014) há uma relação mútua entre a fome, pobreza e a SAN, o que não pode ser sintetizado apenas à falta de renda. O autor acrescenta que para reduzir a vulnerabilidade em que as famílias se encontram e fazer com que o PBF não se limite apenas a um caráter assistencialista e emergencial, urge a necessidade de se incorporar estratégias por parte dos governos, a exemplo, investir nos setores de saúde, educação e geração de trabalho e renda.

Considerando a amplitude do conceito de SAN proposto pela LOSAN, pode se dizer que esta condição, identificada pela EBIA em 5,7\% das famílias estudadas, reflete apenas o acesso aos alimentos em sua dimensão quantitativa. Nessa perspectiva, Azevedo e Ribas (2016) apontam que o conceito de SAN ultrapassa o aspecto biologicista e quantitativo, tomando para si a ideia de qualidade de alimentos, livres de contaminantes biológicos, genéticos, físicos e químicos, ajustados de acordo com a cultura da região onde são produzidos. Além disso, há o interesse de garantir a segurança e dignidade das pessoas envolvidas na produção do alimento.

Por ser uma escala de IAN, a EBIA não é capaz de captar questões referentes à qualidade da alimentação. Esse instrumento está voltado a questões relacionadas ao acesso econômico e físico ao alimento, o que impossibilita avaliar se este acesso garante uma alimentação nutricionalmente adequada e saudável (ALMEIDA; SPERANDIO; PRIORE, 2014).

Ademais, a aplicação da EBIA e outros indicadores utilizados para detectar seus níveis não são capazes de identificar o desiquilíbrio e a erosão cultural da dieta e dos sistemas alimentares ou a contaminação química e genética dos alimentos, como elementos de insegurança (AZEVEDO; RIBAS, 2016). Dito isto, a concepção que auxilia a EBIA relaciona-se mais à carência de alimentos a nível domiciliar e menos a SAN (BURLANDY; SALLES-COSTA, 2007)

\subsection{Caracterização socioeconômica e demográfica}

A IAN é causada por vários fatores, por isso, seu enfrentamento e a definição de estratégias precisam ser direcionados a cada contexto, de forma específica. Para tanto, é essencial se informar sobre as particularidades dos grupos populacionais e sua associação ou 
não com a IAN (SANCHES, 2012). De acordo com Suzart et al. (2017), os fatores sociodemográficos e econômicos (raça/cor, renda, escolaridade, situação no mercado de trabalho, composição familiar) e os ambientais (características da moradia e condições sanitárias dos domicílios) estão fortemente associados à IAN.

Dito isto, a amostra do presente estudo foi constituída em sua maior parte por pessoas do sexo feminino, resultado similar a outros estudos (ANIZIELI et al., 2015; CARMO et al., 2016; NASCIMENTO et al., 2017) o que pode ser justificado pelo fato de as mulheres terem preferência na concessão de titularidade do cartão (IBASE, 2008). Com isso, o BF contribui para que essas beneficiárias tenham autonomia, bem como, coopera para superação da cultura de resignação e de dominação de gênero e potencializa a cidadania (BRASIL, 2013).

Em relação à cor/raça, houve predomínio de participantes que se autodeclararam pardos. Este dado se assemelha ao encontrado em estudo de base populacional realizado em diversas regiões do Brasil, que ao analisar o perfil de titulares do PBF e suas famílias, observou que a maioria (64\%) dos(as) titulares são pretos ou pardos (IBASE, 2008). Também, na Pesquisa Nacional por Amostra de Domicílios - PNAD (2013) foi encontrada maior prevalência de IAN nos domicílios em que os residentes se autodeclararam pretos ou pardos.

Outros estudos que envolveram população de baixa renda também apontam um maior percentual de indivíduos que referiam cor/raça parda (IBGE, 2010; FACCHINI et al., 2014; ZIMMERMAN; SPINDOLA, 2015; OLIVEIRA et al., 2017), o que pode ser explicado pela demasiada diferença entre os indivíduos de cor ou raça distintas, onde há maior permanência de não brancos nos estratos mais baixos (IBGE, 2013).

Outra condição importante verificada neste estudo foi o baixo nível de escolaridade entre os titulares do benefício. Este dado assemelha-se ao encontrado por Suzart et al. (2017), ao investigarem os impactos do PBF quanto aos aspectos de SAN em famílias beneficiárias residentes no município de Vitória da Conquista, BA. Outrossim, diferentes estudos realizados com beneficiários do PBF verificaram menor grau de escolaridade entre a população estudada (ANSCHAU; MATSUO; SEGALL-CORRÊA, 2012; FACCHINI et al., 2014; FERREIRA; MAGALHÃES, 2017; NASCIMENTO et al., 2017).

À vista disso, diversos estudos têm evidenciado que famílias cujas mães apresentam menos de 8 anos de estudos possuem mais chances de ter IA (IBGE, 2010; FACCHINI et al., 2014; MONTEIRO et al., 2014; SPERANDIO; PRIORE, 2015; PACHECO et al., 2018). Isto pode ser justificado pela dificuldade encontrada por indivíduos com baixa escolaridade em 
inserir-se no mercado de trabalho formal, o que resulta o acesso a empregos com baixa remuneração, podendo cooperar para a ocorrência de IAN (SPERANDIO; PRIORE, 2015).

Nessa conjuntura, ressalta-se, que o nível de escolaridade condiciona sobre o ensejo de empregos e salários, consequentemente aperfeiçoa o uso da renda e torna viável o acesso aos bens e serviços básicos à manutenção da saúde, tais como, alimentação e moradia (MONTEIRO et al., 2014). Assim sendo, Ferreira et al. (2014) discutem que a baixa escolaridade da pessoa de referência pode impactar de forma negativa na qualidade da alimentação, por falta de acesso à informação adequada, o que dificulta na escolha de alimentos saudáveis.

Cabe destacar, que não somente a baixa escolaridade condiciona a trabalhos com menor remuneração, o qual é agravado pela condição histórica das mulheres terem menor rendimento que os homens, quando exercem os mesmos cargos. Silva Filho, Queiroz e Clementino (2016) ao analisarem a participação feminina no mercado de trabalho metropolitano brasileiro, observaram que as mulheres ainda são maioria no mercado informal e recebem os piores salários. Tal conjuntura reverbera no aumento das dificuldades financeiras, influenciando negativamente na aquisição alimentícia em domicílios chefiados por mulheres (SANTOS et al., 2018).

Dentro desse contexto, destaca-se que as mulheres além de serem mais propensas à ocupação de postos de trabalho na informalidade, são mais vulneráveis ao desemprego. Logo, a maioria dos participantes do presente estudo estava inativa. Considerou-se inativos, todos que estavam desempregados ou no trabalho informal. Dentre os que relataram trabalhar na informalidade, foram citados trabalhos como: faxina, diarista, babá, reciclagem, pintor, panfletagem, manicure e montadora de sacola. Os resultados encontrados por Ferreira e Magalhães (2017) corroboram com estes achados, nos quais os autores verificaram que as participantes de seu estudo estavam inseridas em ocupações de pouco prestígio.

Assim sendo, a renda dessas famílias consequentemente eram comprometidas. Deste modo, quando questionadas em relação à renda familiar, quase metade referiu obter um valor menor ou igual a um salário mínimo mensal, somado ao valor do benefício. Resultado semelhante foi encontrado por Nascimento et al. (2017) ao avaliarem as relações do PBF com a SAN, a alimentação, o consumo e o modo de vida das famílias no Território do Marajó. Historicamente, a população de cor/raça preta/parda apresenta maior vulnerabilidade às desigualdades socioeconômicas, como exemplo a distribuição desigual da renda, o que repercute negativamente na SAN (SUZART et al., 2017). 
Os gastos com a alimentação, por parte predominante das famílias, eram menores que quatrocentos reais mensais, o que, somado à pouca informação sobre uso correto dos recursos para a alimentação, poderia contribuir para piores escolhas e aquisição de menor variedade dos alimentos.

Ressalta-se ainda, que preponderantemente, as famílias do presente estudo tinham gastos com moradia, seja na forma de aluguel ou prestações de financiamento habitacional, o que comprometia ainda mais a renda. É sabido que a renda familiar se constitui como um fator importante na determinação da IA (CABRAL et al., 2014). Nessa lógica, os resultados da PNAD (2013) evidenciaram que quanto menor for o rendimento mensal domiciliar per capita, maior a proporção de domicílios com IA (IBGE, 2014).

Quanto à classificação econômica segundo os critérios da ABEP (2016), observou se que a maioria das famílias se enquadrou nos níveis intermediários (B2, C1, C2), fato que chamou atenção, visto que, por ser uma população em situação de vulnerabilidade, esperava-se que a parte preponderante fosse classificada nas classes inferiores como verificado em outros estudos (ANSCHAU; MATSUO; SEGALL-CORRÊA, 2012; SUZART; FERREIRA, 2018). Para esclarecer este achado, estudo de coorte, que avaliou o impacto do PBF na superação da IAN, ao analisar a relação entre a renda e o recebimento do benefício do PBF, concluiu que o acréscimo da renda entre os beneficiários pode colaborar na melhoria do perfil econômico (CABRAL et al., 2014).

Assim, com o incremento da renda familiar e por meio das condicionalidades propostas, o PBF almeja ampliar os direitos sociais dos cidadãos, reduzir a pobreza e a fome, aumentar a capacidade de acesso aos alimentos pela população em vulnerabilidade social e, auxiliar na promoção da SAN (COTTA; MACHADO, 2013; ALMEIDA; SPERANDIO; PRIORE, 2014; CABRAL et al., 2014). Porém, o que infelizmente tem sido verificado, é que nem sempre o aumento do acesso aos alimentos é acompanhado por uma melhora na qualidade nutricional da alimentação (COTTA; MACHADO, 2013; ALMEIDA; SPERANDIO; PRIORE, 2014).

De acordo com a pesquisa do Instituto Brasileiro de Análises Sociais e Econômicas (IBASE), no qual avaliou as modificações no consumo alimentar das famílias beneficiárias do PBF, houve aumento no consumo de alimentos em quantidade e variedade após recebimento do benefício. Entretanto, sobressaiu a escolha por alimentos de maior densidade calórica e menor valor nutritivo, o que contribui para o aumento de certos tipos de cânceres, como também, doenças crônicas, excesso de peso e obesidade (IBASE, 2008). 
Posto isto, na análise presente mais de $70 \%$ dos titulares participantes do estudo, estavam com excesso de peso, segundo o Índice de Massa Corporal (IMC). Destaca-se, que ao analisar os estudos disponíveis na literatura, houve dificuldade em obter pesquisas que avaliaram o estado nutricional dos titulares.

Nesse sentido, estudo de base populacional realizado em Curitiba, Paraná, cujo objetivo foi de descrever o estado nutricional da população adulta inscrita no PBF, constatou que $56,1 \%$ dos participantes da pesquisa apresentavam excesso de peso (LIMA; RABITO; DIAS, 2011). Prevalência similar (53,5\%) também foi encontrada em Montes Claros, Minas Gerais (MONTEIRO; SOUZA; PINHO, 2014). Da mesma forma, resultado semelhante à presente pesquisa, foi encontrado em estudo, que ao avaliar o estado nutricional de beneficiários do PBF em uma UBS de Caxias do Sul, constatou que $77 \%$ dos titulares do benefício apresentavam excesso de peso (MASCHIO; OLIVEIRA; GREGOLETTO, 2014).

Corroborando com os resultados encontrados, a Pesquisa de Orçamentos Familiares (POF) realizada nos anos 2008-2009 evidenciou que o excesso de peso estava presente em 50,1\% da população brasileira (IBGE, 2010). Posteriormente, a Pesquisa Nacional de Saúde (PNS), identificou aumento desta condição, atingindo 56,9\% dos brasileiros (IBGE, 2015). Da mesma forma, a Pesquisa de Vigilância de Fatores de Risco e Proteção para Doenças crônicas por Inquérito Telefônico (VIGITEL) de 2016 aponta que mais da metade da população $(55,7 \%)$ tem excesso de peso (BRASIL, 2017).

$\mathrm{O}$ excesso de peso é um agravo nutricional determinado por aspectos individuais, tais como a qualidade nutricional da alimentação e o gasto energético, que sofrem influências de forma intensa pelas realidades domiciliares, a exemplo a IAN vivenciada pelas famílias e tipo de alimentos disponíveis para consumo (VALENTE et al., 2019). Assim, famílias pobres que possuem um acréscimo na renda, gastam mais com alimentos ricos em açucares e gorduras, podendo ser esta umas das principais causas do número expressivo de indivíduos com excesso de peso observado nessa população (SALDANHA et al. (2014).

Ferreira e Magalhães (2017) ao investigarem as práticas alimentares de um grupo de mulheres pobres e obesas, titulares do PBF, observaram modificações favoráveis referentes ao aumento dos gastos com alimentação, maior número de refeições realizadas pelas famílias e acréscimo da variedade de alimentos consumidos. Em contrapartida, constataram que muitas famílias estavam em condição de IAN, bem como, verificaram consumo de alimentos calóricos e pouco nutritivos, o que tem cooperado para agravar o excesso de peso nessa população. 
Desse modo, torna-se evidente uma maior prevalência de comportamentos não saudáveis entre grupos com o menor nível socioeconômico (ANIZELLI et al., 2015), o que se justifica, segundo os autores, pelo orçamento restrito e a baixa renda que esta população apresenta (SPERANDIO et al., 2017).

Outros fatores contribuem para o aumento do excesso de peso em populações de baixa renda com alta prevalência de IAN, dentre eles estão as alterações metabólicas que decorrem da má condição nutricional no início da vida, favorecendo o balanço energético positivo e ganho de peso na fase adulta; as condições psicológicas associadas ao estresse da pobreza; e/ou a redução da atividade física. (CABRAL et al., 2013).

Nesse contexto, Kepple e Segall-Corrêa (2011) colocam que ao invés de definir o sobrepeso como sendo um problema oposto a fome, é preciso considerar a possibilidade de que seja uma consequência dela em populações de baixa renda.

Pesquisas apontam a associação de IAN com número de moradores no domicílio, onde se verifica maior probabilidade de ocorrência da mesma entre famílias com maior número de indivíduos (MONTEIRO et al., 2014; SPERANDIO; PRIORE, 2015; BEZERRA; OLINDA; PEDRAZA, 2017). Isso se deve ao fato de famílias numerosas precisarem de mais recursos para a compra de alimentos (BEZERRA; OLINDA; PEDRAZA, 2017).

Entretanto, no presente estudo, observou-se que as famílias em sua maioria eram pouco numerosas, compostas por até quatro moradores. Dados similares foram descritos em estudos realizados com beneficiários do PBF no município de Colombo, PR e no território do Marajó, PA (MONTEIRO et al., 2014, NASCIMENTO et al., 2017).

De acordo com Bezerra, Olinda e Pedraza (2017), o tipo de moradia também tem sido evidenciado como condicionante importante da IAN, o que pode estar ligado aos determinantes demográficos e fatores socioeconômicos que exercem influência sobre esta condição. Dentro desse contexto, famílias que residem em moradias em situações precárias estão vulneráveis a IAN (MONTEIRO et al., 2014; SPERANDIO; PRIORE, 2015; BEZERRA; OLINDA; PEDRAZA, 2017). As famílias estudadas preponderantemente moravam em casas ou apartamentos próprios, de alvenaria acabada, com quatro ou mais cômodos.

No que se refere às condições sanitárias, os resultados encontrados foram satisfatórios, isto se deve à boa condição de saneamento básico verificada no município, onde aproximadamente $100 \%$ dos domicílios urbanos possuem água encanada, esgotamento 
sanitário e coleta de lixo com destino a aterros sanitários (PREFEITURA MUNICIPAL DE RIBEIRÃO PRETO, 2020)

Por fim, os resultados do presente estudo, apontam que a IAN atinge as famílias de uma forma geral, não tendo associação a uma variável específica, sendo relevante e consistente. Nesse sentido, a intervenção deve ser trabalhada de forma universal.

\subsection{Bolsa Família e recebimento de outros benefícios}

O PBF almeja dotar os beneficiários de capital humano para romper o ciclo intergeracional da pobreza em longo prazo. Porém, apesar de o Programa ter apresentado êxito na redução da severidade da pobreza em termos econômicos e proporcionado acesso a serviços básicos, os baixos valores transferidos não são suficientes para concretizar a saída desta condição multifatorial de pobreza (ZIMMERMANN; ESPÍNOLA, 2015).

Dentro dessa perspectiva, se justifica os resultados encontrados na presente análise, nos quais, parte preponderante das famílias referiu receber até duzentos reais mensais. Quanto ao tempo de recebimento do benefício, houve predomínio de famílias que recebiam há mais de quatro anos.

Sabe-se que não há um tempo definido para que ocorra a emancipação dos beneficiários. Contudo, observou-se que há famílias que estão no programa há mais de oito anos, o que pode indicar falhas no processo de inclusão social, sendo necessário rever o papel do Estado na promoção da cidadania.

Resultados semelhantes ao presente estudo foram encontrados por Zimmermann e Espínola (2015) ao estudarem o BF pautados na percepção dos beneficiários. Os autores verificaram que entre as beneficiárias estudadas, a maioria recebiam baixos valores, os quais eram insuficientes para fazer frente às condições de pobreza. Ademais, concluíram que o benefício é extremamente importante para as famílias pobres, pois atende as necessidades imediatas, porém, os baixos valores transferidos e à falta de programas complementares o torna incapaz de retirar as famílias da situação de pobreza. Assim como os autores supracitados, Ferreira e Magalhães (2017) constataram que o BF assume um lugar indispensável na alimentação dos beneficiários, visto que ele ameniza em algum grau situações extremas de privação.

É importante reforçar que o grau de escolaridade além de ser um fator determinante para uma boa colocação no mercado de trabalho, é fundamental para a mobilidade social. Outro 
ponto a acrescentar, se refere a uma das críticas ao BF, no qual sugere que o programa incita a ociosidade dos beneficiários e pode desencorajar a busca ou mesmo o investimento pessoal com vista a obter melhores oportunidades de trabalho (ZIMMERMANN; ESPÍNOLA, 2015).

Kerstenetzky (2009) destaca que a ausência de expectativas concretas de inserção social, tanto dos beneficiários quanto dos elegíveis, impulsiona o crescimento e a permanência no programa por um longo período.

Desse modo, para que as famílias beneficiárias do BF rompam a linha da pobreza, é preciso investir na capacitação dessa população e na disponibilização de oportunidades trabalhistas efetivas e reais, o que ainda é pouco considerado pelos programas de transferência de renda da América Latina (ZIMMERMANN; ESPÍNOLA, 2015).

Ademais, Traldi, Almeida e Ferrante (2012) refere que para que ocorra a emancipação das famílias é necessário a integração do PBF com outros programas sociais, com a finalidade de promover a SAN; bem como o investimento na saúde; na educação; na capacitação dos beneficiários.

Para tanto, considera-se fundamental estabelecer e intensificar estratégias de comunicação entre os beneficiários, gestores locais e sociedade; repensar as condicionalidades, inserindo a questão da SAN dos beneficiários; integrar com políticas que proporcionem oportunidade de trabalho e renda; e melhorar a qualidade da alimentação através de ações de educação alimentar (TRALDI; ALMEIDA; FERRANTE, 2012), haja vista que a maior parte dos benefícios das famílias estudadas é destinada para a alimentação (IBASE, 2008; TRALDI; ALMEIDA; FERRANE, 2012; ANIZIELLI et al., 2015; ZIMMERMANN; ESPÍNOLA, 2015; FERREIRA; MAGALHÃES, 2017).

Segundo Carmo et al. (2016), com o incremento da renda, as famílias beneficiárias do PBF estão tendo maior acesso aos alimentos, porém, isso não é garantia de que a alimentação seja adequada em termos de qualidade. Nascimento et al. (2017) ao analisarem o papel que o PBF desenvolve na SAN das famílias do Território do Marajó, PA, observaram que entre os principais produtos adquiridos pelas famílias estudadas, estavam a carne vermelha, arroz, feijão, açúcar, café e produtos industrializados, como, refrigerantes, salsicha, carne enlatada e macarrão instantâneo.

Outros estudos, desenvolvidos com beneficiários do PBF, evidenciaram que entre as estratégias de consumo alimentar adotadas pela população estudada, estava a preferência por um cardápio monótono, composto por alimentos baratos, de alta densidade calórica e alto índice glicêmico, como refrigerante, biscoito, farinha de milho e macarrão, como também 
alimentos à base de açucares e gorduras. (CABRAL et al., 2013; ALMEIDA; SPERANDIO; PRIORE, 2014; CARMO et al., 2016; FERREIRA; MAGALHÃES, 2017)

A escolha por alimentos ultraprocessados é justificada pelo baixo custo, praticidade, conveniência, saciedade e maior aceitação por parte das crianças e dos jovens (FERREIRA; MAGALHÃES, 2017; NASCIMENTO et al., 2017).

Além da renda, alguns fatores interferem na escolha alimentar. Dentre eles, o marketing se apresenta como um potencial veículo de incentivo ao consumo de alimentos não saudáveis (ALMEIDA; SPERANDIO; PRIORE, 2014). Outro ponto a acrescentar é a falta de acesso à informação, que contribui para erros alimentares.

No que se refere ao benefício recebido, embora este seja insuficiente para assegurar o alimento durante todo o mês, colabora para amenizar a situação de escassez alimentar verificada nessa população. À vista disso, para complementar a alimentação, algumas famílias referiram receber concomitante ao $\mathrm{BF}$, doações de cestas básicas e/ou leite oriundos de familiares/assistente social e governo. Resultados encontrados por Traldi, Almeida e Ferrante (2012), em estudo sobre as repercussões do PBF no município de Araraquara, corroboram com estes achados. Posto isto, em situações de carência alimentar, a solidariedade entre a população resulta em uma rede de apoio (IBASE, 2008).

\subsection{Estado nutricional das crianças}

As crianças são as principais beneficiárias do PBF. Desse modo, caso as mães não tenham acesso a informações que contribuam para aplicação de práticas alimentares adequadas, bem como façam uso impróprio do benefício, as crianças poderão ter comprometida sua condição nutricional, apresentar dificuldades de aprendizagem, pior rendimento escolar, maior vulnerabilidade a doenças e maior risco de mortalidade (ANIZIELLI et al., 2015).

De acordo com Monteiro et al (2014), a avaliação do estado nutricional das crianças se constitui em uma medida indireta para avaliar a qualidade de vida e saúde da população infantil, sendo utilizada em caráter complementar à avaliação da IA.

Nesse sentido, para a avaliação do estado nutricional das crianças, os índices antropométricos P/I; P/E; E/I e IMC/I são os que largamente são utilizados, sendo recomendados pela OMS e adotados pelo Ministério da Saúde (BRASIL, 2011). Destaca-se que o P/I exprime a relação entre a massa corporal e a idade cronológica da criança, o qual é utilizado para avaliar o estado nutricional, em especial para avaliação do baixo peso. É 
apropriado para acompanhar o ganho de peso e reflete a situação da criança como um todo, não diferenciando o comprometimento nutricional atual ou agudo dos pregressos ou crônicos (BRASIL, 2011). Segundo esse índice, a maioria das crianças avaliadas estavam com P/I adequado para a idade.

Já a E/I expressa o crescimento linear da criança. Este índice é o que melhor indica o efeito cumulativo de situações adversas sobre o crescimento da criança, sendo considerado o indicador mais sensível para aferir a qualidade de vida de uma população (BRASIL, 2011). A partir desse índice, constatou-se o predomínio de crianças com estatura adequada para idade. Porém, apesar dos achados sugerirem uma melhora progressiva nas condições de vida da população estudada, observou-se que 3,9\% apresentavam baixa estatura para idade.

Para identificar o excesso de peso entre as crianças são utilizados os índices P/E (expressa a concórdia entre as dimensões de massa corporal e estatura) e IMC/I (exprime a relação entre o peso da criança e o quadrado da estatura) (BRASIL, 2011). A partir destes índices observou-se que aproximadamente $25 \%$ das crianças apresentavam risco de desenvolver excesso de peso ou já se encontravam nessa condição.

Em suma, há uma porcentagem expressiva de crianças em condição de excesso de peso. Estes resultados se assemelham aos encontrados na Pesquisa de Orçamentos Familiares (POF) realizada nos anos 2008-2009, no qual se verificou que entre as crianças de cinco a nove anos houve prevalências de $33,5 \%$ e $14,3 \%$ de excesso de peso e obesidade respectivamente.

Resultados semelhantes aos do presente estudo foram encontrados por Carmo et al. (2016), ao analisarem a frequência alimentar e estado nutricional entre escolares, segundo a participação no PBF, nos quais houve uma prevalência de 30,7\% de excesso de peso entre beneficiários. Da mesma forma, ao analisar o perfil epidemiológico nutricional de crianças menores de cinco anos atendidas pela Estratégia Saúde da Família (ESF) no Maranhão - MA, foi verificado o excesso de peso em 23,2\% (LOPES et al., 2019). Outros estudos também corroboram com os achados da presente pesquisa (SALDANHA et al., 2014; SILVA; NUNES, 2015; FREITAS et al., 2017; SPERANDIO et al., 2017), evidenciando assim, a crescente prevalência de excesso de peso entre a população de baixa renda, corroborando com o fenômeno da transição nutricional verificado no país.

Posto isto, Carmo et al. (2016) sugere que o aumento considerável do excesso de peso infantil verificado nas classes de baixa renda se deve ao aumento no consumo de alimentos de alta densidade energética, seja pelo baixo preço desses alimentos e/ou pela falta de conhecimento relativo ao que seria uma alimentação saudável. 
Ademais, como exposto anteriormente, além desses fatores, a baixa escolaridade, praticidade e a mídia também influenciam negativamente nas escolhas alimentares. Segundo Almeida, Sperandio e Priore (2014), as crianças são as mais afetadas pela publicidade de alimentos, visto que os hábitos alimentares estão sendo formados na infância e sofrem influência de diversos fatores, os quais se inclui a mídia. 


\section{CONCLUSÃO}

As famílias beneficiárias do PBF do Distrito Sanitário Oeste do município de Ribeirão Preto apresentaram alta prevalência de IAN, com destaque para IAM e IAG que somadas atingiram mais da metade da população estudada, o que sugere situação de privação alimentar e/ou fome experimentadas pelas famílias, evidenciando assim, a alta vulnerabilidade dessa população.

Diante dos resultados das análises, verificou-se que a IAN ocorre de maneira geral, não estando associada a nenhuma variável específica. Desta forma, sua intervenção deve ser trabalhada de modo universal.

A expressiva taxa de excesso de peso verificada nos titulares do benefício, assim como nas crianças, indica para o processo de transição nutricional que está impactando o mundo, em especial o Brasil. Nesse contexto, urge a necessidade de estratégias de promoção de Educação Alimentar e Nutricional direcionada a essa população.

Em suma, o PBF é de extrema importância para seus beneficiários, porém, sozinho, não é capaz de retirá-los da condição multidimensional de pobreza em que se encontram.

Espera-se que através dos resultados obtidos, o presente estudo possa contribuir para melhora da condição de vida/saúde dos beneficiários do PBF do município de Ribeirão Preto, bem como, do país. 


\section{REFERÊNCIAS}

ABEP. ASSOCIAÇÃO BRASILEIRA DE EMPRESAS DE PESQUISA. Critério Brasil 2015 e atualização da distribuição de classes para 2016. Critério de classificação econômica Brasil, p. 1-6, 2016.

ALMEIDA, I. S.; SPERANDIO, N.; PRIORE, S. E. Qualidade da dieta de pré-escolares beneficiados pelo Programa Bolsa Família, segundo a situação de Segurança Alimentar do domicílio. Nutrire, São Paulo, v. 39, n.3, p. 297-305, 2014.

ANIZELLI, C. P. et al. Condições de vida e aquisição de gêneros alimentícios de crianças beneficiárias do programa bolsa família. Revista Baiana de Saúde Pública, Bahia, v. 39, n. 1, p. 74-87, 2015.

ANSCHAU, F. R.; MATSUO, T.; SEGALL-CORRÊA, A. M. Insegurança alimentar entre beneficiários de programas de transferência de renda. Revista de Nutricao, Campinas, v. 25, n. 2, p. 177-189, 2012.

AZEVEDO, E.; RIBAS, M. T.G. O. Estamos seguros? Reflexões sobre indicadores de avaliação da segurança alimentar e nutricional. Revista de Nutrição, Campinas, v. 29, n. 2, p. 241-251, 2016.

BARBOSA, N. M. U. et al. Programa bolsa família: a condicionante saúde realmente existe?. Revista Brasileira de Promoção da Saúde, Fortaleza, v. 27, n.4, p. 435-436, 2014.

BARROS, K. C. S. et al. Perfil Socioeconômico e Nutricional de Escolares em (In)Segurança Alimentar de uma Região do Semiárido Nordestino. Revista Brasileira de Ciências da Saúde, João Pessoa, v. 20, n. 1, p. 5-10, 2016.

BATISTA-FILHO, M.; RISSIN, A. Nutritional transition in Brazil: geographic and temporal trends. Cadernos de Saúde Pública, v.19, n. suppl 1, p. S181-S191, 2003.

BELIK, W. Perspectivas para segurança alimentar e nutricional no Brasil. Saúde e Sociedade, São Paulo, v. 12, n. 1, p. 12-20, 2003.

BELIK, W. A Crise dos Alimentos e os Agravantes para a Fome Mundial. Mundo Agrario, Buenos Aires, v. 14, n. 27, 2013.

BEZERRA, T. A.; PEDRAZA, D. F. (In)segurança alimentar entre famílias com crianças menores de cinco anos residentes em área de vulnerabilidade social de Campina Grande, Paraíba. Revista de Nutrição, Campinas, v. 28, n. 6, p. 655-665, 2015.

BEZERRA, T. A.; OLINDA, R. A. DE; PEDRAZA, D. F. Insegurança alimentar no Brasil segundo diferentes cenários sociodemográficos. Ciência \& Saúde Coletiva, Rio de Janeiro, v. 22, n. 2, p. 637-651, 2017.

BRASIL. Lei n ${ }^{\circ} 10.836$ de 9 de Janeiro de 2004. Cria o Programa Bolsa Família e dá outras providências. Diário Oficial da União, Brasília, DF, 9 jan. 2004. 
BRASIL. Lei no 11.346 de 15 de Setembro de 2006. Cria o Sistema de Segurança Alimentar e Nutricional - SISAN com vistas a assegurar o direito humano à alimentação adequada e dá outras providências. Diário Oficial da União, Brasília, DF, 15 set. 2006.

BRASIL. Ministério da Saúde. Protocolos do Sistema de Vigilância Alimentar e Nutricional - SISVAN na assistência à saúde. Brasília: Secretaria de Atenção à Saúde, 2008.

BRASIL. Emenda Constitucional $n^{\circ} 64$ de 4 de Fevereiro de 2010. Altera o art. $6^{\circ}$ da Constituição Federal, para introduzir a alimentação como um direito social. Diário Oficial da União, Brasília, DF, 4 fev. 2010

BRASIL. Ministério da Saúde. Orientações para coleta e análise de dados antropométricos em serviços de saúde: norma técnica do sistema de Vigilância Alimentar e Nutricional - SISVAN. Brasília: Ministério da Saúde, 2011. (Série G. Estatística e Informação em Saúde).

BRASIL. Ministério do Desenvolvimento Social e Combate à Fome. Bolsa Família: Transferência de renda e apoio à família no acesso à saúde, à educação e à assistência social. Brasília: Ministério do Desenvolvimento Social e Combate à Fome, 2013.

BRASIL. Ministério do Desenvolvimento Social e Combate a Fome. Escala Brasileira de Insegurança Alimentar - EBIA: análise psicométrica de uma dimensão da Segurança Alimentar e Nutricional. Brasília: Secretaria de Avaliação e Gestão da Informação, 2014.

BRASIL. Ministério da Saúde. Estimativas sobre frequência e distribuição sóciodemográfica de fatores de risco e proteção para doenças crônicas nas capitais dos 26 estados brasileiros e no Distrito Federal em 2016. Brasília: Vigilância de Fatores de Risco e Proteção para Doenças Crônicas por Inquérito Telefônico - VIGITEL, 2017.

BRASIL. Ministério do Desenvolvimento Social. Manual do Pesquisador - Programa Bolsa Família Brasília: Ministério do Desenvolvimento Social, 2018.

BRASIL. Ministério da Cidadania. Secretaria Especial do Desenvolvimento Social. Bolsa Família. Disponível em: < http://www.desenvolvimentosocial.gov.br/>. Acesso em: 10 jan. 2020.

BURLANDY, L.; SALLES-COSTA, R. Segurança alimentar e nutricional: concepções e desenhos de investigação. In: Kac G, Sichieri R, Gigante D, organizadores. Epidemiologia nutricional. Rio de Janeiro: Fiocruz; 2007. p.485-502

CABRAL, M. J et al. Perfil socioeconômico, nutricional e de ingestão alimentar de beneficiários do Programa Bolsa Família. Estudos Avançados, São Paulo, v. 27, n. 78, p. 71$88,2013$.

CABRAL, C. S. et al. Food security, income, and the Bolsa Família program: a cohort study of municipalities in Paraíba State, Brazil, 2005-2011. Cadernos de saúde pública, Rio de Janeiro, v. 30, n. 2, p. 393-402, 2014. 
CARDOSO, L. J. Crescimento alcançado e estado nutricional de escolares. Archivos Latinoamericanos de Nutrición, v. 67, n. 2, p. 116-121, 2017.

CARMO, A. S. et al. Influence of the Bolsa Família program on nutritional status and food frequency of schoolchildren. Jornal de Pediatria, Rio de Janeiro, v. 92, n. 4, p. 381-387, 2016.

CONFERÊNCIA NACIONAL DE SEGURANÇA ALIMENTAR E NUTRICIONAL, 2: A Construção da Política Nacional de Segurança Alimentar e Nutricional: Relatório final. Olinda: CNSAN, 2004. 48 p.

COLUCCI, M. DA G.; TONIN, M. M. Direito Humano À Alimentação Adequada e a Segurança Alimentar e Nutricional da Criança e do Adolescente. p. 2323-2337, 2006.

CONSELHO NACIONAL DE SEGURANÇA ALIMENTAR . I Conferência Nacional de Segurança Alimentar. Brasília: CONSEA, 1995. 102 p.

COTTA, R. M. M.; MACHADO, J. C. The Bolsa Família cash transfer program and food and nutrition security in Brazil: a critical review of the literature. Revista panamericana de salud pública = Pan American journal of public health, Washington, v. 33, n. 1, p. 54-60, 2013.

FACCHINI, L. A. et al. Insegurança alimentar no Nordeste e Sul do Brasil: magnitude, fatores associados e padrões de renda per capita para redução das iniquidades. Cadernos de Saúde Pública, Rio de Janeiro, v. 30, n. 1, p. 161-174, 2014.

FOOD AND AGRICULTURE ORGANIZATION. Declaração de Roma sobre a Segurança Alimentar Mundiasl e Plano de Ação da Cimeira Mundial da Alimentação. Cimeira Mundial da Alimentação, 13 a 17 de Novembro. Roma: FAO, 1996.

FERREIRA, H. S. et al. Prevalência e fatores associados à Insegurança Alimentar e Nutricional em famílias dos municípios do norte de Alagoas, Brasil, 2010. Ciência \& Saúde Coletiva, Rio de Janeiro, v. 19, n. 5, p. 1533-1542, 2014.

FERREIRA, V. A.; MAGALHÃES, R. Práticas alimentares de mulheres beneficiárias do Programa Bolsa Família na perspectiva da promoção da saúde. Revista Saúde e Sociedade, São Paulo, v. 26, n. 4, p. 987-998, 2017.

FREITAS, A. G. et al. Comparação do estado nutricional em crianças de cinco a dez anos de idade beneficiárias do Programa de transferência de dinheiro condicional nos Estados do Acre e do Rio Grande do Sul, Brasil. J Hum Growth Dev, v. 27, n. 1, p. 35-41, 2017.

INSTITUTO BRASILEIRO DE ANÁLISES SOCIAIS E ECONÔMICAS. Repercussões do Programa Bolsa Família na segurança alimentar e nutricional das famílias beneficiadas. Rio de Janeiro: IBASE, 2008. 21 p.

INSTITUTO BRASILEIRO DE GEOGRAFIA E ESTATÍSTICA. Estudo Nacional de Despesa Familiar: Endef. Rio de Janeiro: IBGE, 1976.

INSTITUTO BRASILEIRO DE GEOGRAFIA E ESTATISTICA. Pesquisa Nacional sobre Saúde e Nutrição - PNSN (1989). IBGE; 7 p.; 1990. 
INSTITUTO BRASILEIRO DE GEOGRAFIA E ESTATISTICA. Pesquisa Nacional por Amostra de Domicílios: Segurança Alimentar 2004. Rio de Janeiro: IBGE, 2006a. 140 p.

INSTITUTO BRASILEIRO DE GEOGRAFIA E ESTATISTICA. Pesquisa de Orçamentos Familiares 2002-2003: antropometria e análise do estado nutricional de crianças e adolescentes no Brasil. Rio de Janeiro: IBGE, 2006b. 140 p.

INSTITUTO BRASILEIRO DE GEOGRAFIA E ESTATISTICA. Pesquisa de Orçamentos Familiares 2008-2009: antropometria e análise do estado nutricional de crianças, adolescentes e adultos no Brasil. Rio de Janeiro: IBGE, 2010. 130 p.

INSTITUTO BRASILEIRO DE GEOGRAFIA E ESTATISTICA. Características Étnicoraciais da População: Classificações e identidades. In: ATHIAS, L. MATOS, G. Mobilidade social. Rio de Janeiro: IBGE, 2013.

INSTITUTO BRASILEIRO DE GEOGRAFIA E ESTATISTICA. Pesquisa Suplementar de Segurança Alimentar - PNAD 2013: A percepção das famílias em relação ao acesso aos alimentos. Rio de Janeiro: IBGE, 2014. 34 p.

INSTITUTO BRASILEIRO DE GEOGRAFIA E ESTATISTICA. Pesquisa Nacional de Saúde: Ciclos de vida - Brasil e grandes regiões. Rio de Janeiro: IBGE, 2015. 90 p.

INSTITUTO BRASILEIRO DE GEOGRAFIA E ESTATISTICA. Estimativa da população 2019. IBGE, 2019a. Disponível em: < https://cidades.ibge.gov.br/brasil/sp/ribeiraopreto/panorama>. Acesso em: 05 jan. 2020.

INSTITUTO BRASILEIRO DE GEOGRAFIA E ESTATISTICA. PNAD Contínua 2018: $10 \%$ da população concentram $\mathbf{4 3 , 1 \%}$ da massa de rendimentos do país. IBGE, 2019b. Disponível em: < https://agenciadenoticias.ibge.gov.br/agencia-sala-de-imprensa/2013agencia-de-noticias/releases/25700-pnad-continua-2018-10-da-populacao-concentram-43-1da-massa-de-rendimentos-do-pais>. Acesso em: 17 jan. 2020.

INSTITUTO DE PESQUISA ECONÔMICA APLICADA. A trajetória histórica da segurança alimentar e nutricional na agenda política nacional: projetos, descontinuidades e consolidação. Rio de Janeiro: IPEA, 2014. 82 p.

KEPPLE, A.; SEGALL-CORRÊA, A. Conceptualizing and measuring food and nutrition security. Ciência \& Saúde Coletiva, Rio de Janeiro, v. 16, n.1, p. 187-199, 2011.

KERSTENETZKY, C. L. Redistribuição e desenvolvimento? A Economia Política do Programa Bolsa Família. Revista de Ciências Sociais, Rio de Janeiro, v. 52, n. 1, p. 53-83, 2009.

LAURENTI, R. Transição demográfica e transição epidemiológica. In: CONGRESSO BRASILEIRO DE EPIDEMIOLOGIA, 1., 1990, Campinas. Anais... Campinas: p. 14365, 1990.

LIMA, F. E. L.; RABITO, E. I.; DIAS, M. R. M. G. Nutritional Status of the adult population in the Bolsa Família Program in Curitiba, State of Paraná, Brazil. Rev Bras Epidemiol, v. 14, n. 2, p. 198-206, 2011. 
LOPES, A. F. et al. Perfil nutricional de crianças no estado do Maranhão. Rev bras epidemiol, São Paulo, v. 22, 2019.

MAGALHÃES, R. Avaliação de políticas e iniciativas públicas de segurança alimentar e nutricional: dilemas e perspectivas metodológicas. Ciência \& Saúde Coletiva, Rio de Janeiro, v. 19, n. 5, 2014.

MAGRANI, L. et al. Insegurança Alimentar E Estado Nutricional Das Famílias Que Recebem Benefícios Sociais Na Unidade De Saúde Da Família Vila Felipe - Petrópolis -. Revista de APS, Juíz de Fora, v. 15, n. 1, p. 29-35, 2012.

MASCHIOA, M. S.; OLIVEIRA, N. F.; GREGOLETTO, M. L. Estado nutricional dos beneficiários do Programa Bolsa Família em uma unidade básica de saúde de Caxias do Sul. In: II Congresso de Pesquisa e Extensão da Faculdade da Serra Gaúcha (FSG), 2014, Caxias do Sul. Anais... Caxias do Sul, 2014.

MONTEIRO, E. L. F.; SOUZA, C. R.; PINHO, L. Diagnóstico de Insegurança Alimentar e Nutricional entre beneficiários do Programa Bolsa Família participantes de oficina de intervenção nutricional. Segurança Alimentar e Nutricional, Campinas, v. 21, n.2, p. 469480, 2014.

MONTEIRO, F. et al. Bolsa Família: insegurança alimentar e nutricional de crianças menores de cinco anos. Ciências \& Saúde Coletiva, Rio de Janeiro, v. 19, n. 5, p. 1347-1357, 2014.

NASCIMENTO, E. C. O. et al. papel do Programa Bolsa Família na segurança alimentar das famílias do Território do Marajó, PA. Interações, Campo Grande, MS, v. 18, n. 2, p. 59-70, 2017.

NETO, V. R. P.; BERRIEL, C. M. Transferências condicionais de renda e nutrição: efeitos do Bolsa Família nas áreas rurais e urbanas do Brasil. Economia Aplicada, v. 21, n. 2, p. 185205, 2017.

OLIVEIRA, D. S. et al. Prevalência e fatores associados à insegurança alimentar. Revista Baiana de Saúde Pública, Bahia, v. 41, n.3, p. 561-579, 2017.

ORGANIZAÇÃO DAS NAÇÕES UNIDAS - ONU. Declaração Universal dos Direitos Humanos. ONU, p. 1-7, 1948.

ORGANIZAÇÃO DAS NAÇÕES UNIDAS - ONU. Comentário Geral No. 12 - O Direito Humano a Alimentação Adequada (art. 11) 1999. In: Valente FL, organizador. Direito humano a alimentação: desafios e conquistas. São Paulo: Cortez; 2002.

ORGANIZAÇÃO MUNDIAL DA SAÚDE - OMS. Novas Curvas de Crescimento. OMS, 2007.

ORGANIZAÇÃO MUNDIAL DA SAÚDE - OMS. Novas Curvas de Crescimento. OMS, 2006. 
PACHECO, P. M. et al. Food and nutritional security of families assisted by the Bolsa Família cash transfer program in primary health care. O mundo da Saúde, São Paulo, v. 42, n.2, p. 459-477, 2018.

PEDRAZA, D. F.; GAMA, J. S. F. Segurança alimentar e nutricional de famílias com crianças menores de cinco anos do município de Campina Grande, Paraíba. Revista Brasileira de Epidemiologia, São Paulo, v. 18, n. 4, p. 906-917, 2015

PEDRAZA, D. F. et al. (In)Segurança alimentar de famílias residentes em um município do interior da Paraíba, brasil. Revista de Salud Pública, Bogotá, v. 19, n.5, p. 649-656, 2017.

PINHEIRO, A. R. O. Reflexões sobre o Processo Histórico / Político de Construção da Lei Orgânica de Segurança Alimentar e Nutricional. Segurança Alimentar e Nutricional, Campinas, v. 15, n. 2, p. 1-15, 2008.

PREFEITURA MUNICIPAL RIBEIRÃO PRETO. Secretaria da Saúde. Revisão das áreas de abrangência das Unidades de Saúde e Estimativa Populacional de acordo com o Censo IBGE 2010 por Unidade. Ribeirão Preto, 2011.

PREFEITURA MUNICIPAL RIBEIRÃO PRETO. Secretaria da Saúde. Rede

Básica. Ribeirão Preto, 2020. Disponível em: <https://www.ribeiraopreto.sp.gov.br/ssaude/rede/i16apresentacao.php>. Acesso em: 12 jan. 2020.

RAMALHO, A. A. et al. Insegurança alimentar em famílias com crianças menores de cinco anos de idade, na fronteira Brasil-Peru. Journal of Human Growth and Development, São Paulo, v. 26, n. 3, p. 307-315, 2016.

RIBEIRO, F. G.; SHIKIDA, C.; HILLBRECHT, O. R. Bolsa Família: Um survey sobre os efeitos do programa de transferência de renda condicionada do Brasil. Estudos Econômicos, São Paulo, v. 47. n.4, p. 805-862, 2017.

SABÓIA, R. C. B.; SANTOS, M. M. Prevalência de insegurança alimentar e fatores associados em domicílios cobertos pela Estratégia Saúde da Família em Teresina, Piauí, 20122013*. Epidemiologia e Serviços de Saúde, Brasília, v. 24, n. 3, p. 749-758, 2015.

SALDANHA, L. F. et al. Nutritional status of children who are recipients of the Family Allowance Program followed up by the Food and Nutrition Surveillance System in the State of Minas Gerais. Revista Médica de Minas Gerais, Belo Horizonte, v. 24, n. 4, p. 478-485, 2014.

SALLES-COSTA, R. et al. Associação entre fatores socioeconômicos e insegurança alimentar: Estudo de base populacional na Região Metropolitana do Rio de Janeiro, Brasil. Revista de Nutricao, Campinas, v. 21, n. SUPPL., p. 99-109, 2008.

SANCHES, A. P. L. M. Insegurança alimentar domiciliar e estado nutricional de crianças de creches municipais de Ribeirão Preto. 2012. Dissertação (Mestrado). Programa de Saúde na Comunidade da Faculdade de Medicina de Ribeirão Preto, Universidade de São Paulo, Ribeirão Preto, 2012. 
SANTOS, T. G. et al. Tendência e fatores associados à insegurança alimentar no Brasil: Pesquisa Nacional por Amostra de Domicílios 2004, 2009 e 2013. Cadernos de Saúde Pública, Rio de Janeiro, v. 34, n.4, p. 1-17, 2018.

SILVA, J. G. DA; GROSSI, M. E. DEL; FRANÇA, C. G. DE. Fome Zero:A experiência brasileira. [s.1: s.n.], 2010.

SILVA, D. A. S. Sobrepeso e obesidade em criancas de cinco a dez anos de idade beneficiarias do programa bolsa familia no estado de Sergipe, Brasil. Revista Paulista de Pediatria, São Paulo, v. 29, n. 4, p. 529-535, 2011.

SILVA, C. C. S. et al. Associação entre consumo alimentar e (in)segurança alimentar e nutricional em São José dos Ramos - PB. Brazilian Journal of Food Technology, Campinas, v. 15, n. spe, p. 23-30, 2012.

SILVA, D. A. S.; NUNES, H. E. G. Prevalência de baixo peso, sobrepeso e obesidade em crianças pobres do Mato Grosso do Sul. Rev Bras Epidemio, São Paulo, v. 18, n. 2, p. 466475, 2015.

SILVA FILHO, L. A.; QUEIROZ, S. N.; CLEMENTINO, M. L. M. Mercado de trabalho nas regiões metropolitanas brasileiras. Revista Mercator, Ceará, v. 15, n.2, p.37-54, 2016.

SIQUEIRA, R. L. Análise da incorporação da perspectiva do Direito Humano à Alimentação Adequada no desenho institucional do Programa Nacional de Alimentação Escolar. Ciência \& Saúde Coletiva, Rio de Janeiro, v. 19, n. 1, p. 301-310, 2014.

SKOV, T. et al. Prevalence proportion ratios: estimation and hypothesis testing. Int J Epidemiol, v. 27, p. 91-95, 1998.

SOARES, F. V.; RIBAS, R. P.; OSÓRIO, R. G. Evaluating the impact of Brasil's Bolsa Família: Cash Transfer Programs in Comparative Perspective. Latin American Research Review, Pittsburgh, v. 45, n. 2, p. 173-190, 2010.

SORTEADOR. Disponível em: < https://www.sorteador.com.br/>. Acesso em: 15 out. 2017.

SOUZA, L. R. M. et al. Food security status in times of financial and political crisis in Brazil. Cadernos de Saúde Pública, Rio de Janeiro, v. 35, n. 7, 2019.

SPERANDIO, N.; PRIORE, S. E. Prevalência de insegurança alimentar domiciliar e fatores associados em famílias com pré-escolares, beneficiárias do Programa Bolsa Família em Viçosa, Minas Gerais, Brasil. Epidemiologia e Serviços de Saúde, Brasília, v. 24, n. 4, p. 739-748, 2015.

SPERANDIO, N. et al. Impact of Bolsa Família Program on the nutritional status of children and adolescents from two Brazilian regions. Revista de Nutrição, Campinas, v. 30, n. 4, p. 477-487, 2017.

SPERANDIO, N.; MORAIS, D. C.; PRIORE, S. E. Escalas de percepção da insegurança alimentar validadas: a experiência dos países da América Latina e Caribe. Ciência \& Saúde Coletiva, Rio de Janeiro, v. 23, n. 2, p. 449-462, 2018. 
SUZART, A. S. et al. Repercussões do programa bolsa família na segurança alimentar e nutricional: um estudo de caso. Revista Baiana de Saúde Pública, Bahia, V. 41, N. 3, P. 699-715, 2017.

SUZART, A. S.; FERREIRA, A. P. Avaliação do Programa Bolsa Família (PBF) na segurança alimentar e nutricional das famílias benefi ciadas, Vitória da Conquista, BA. Interações, Campo Grande, MS, v. 19, n. 3, p. 585-595, 2018.

TEO, C. R. P. A. et al. Direito humano à alimentação adequada: percepções e práticas de nutricionistas a partir do ambiente escolar. Revista Trabalho, Educação e Saúde, Rio de Janeiro, v. 15, n.1, p. 245-267, 2017.

The SAS system for Windows. Release 9.2. SAS Inst., Cary, NC. 2011.

TRALDI, D. R. C.; ALMEIDA, L. M. DE M. C.; FERRANTE, V. L. S. B. Repercussões do Programa Bolsa Família no município de Araraquara, SP : um olhar sobre a segurança alimentar e nutricional dos bene fi ciários Repercussions of the Bolsa Familia Program in the city of Araraquara, SP : a look at food security and nutriti. Interações, Campo Grande, v. 13, n. 1, p. 23-37, 2012.

UNIVERSIDADE DE SÃO PAULO. Faculdade de Economia, Administração e Contabilidade de Ribeirão Preto. História de Ribeirão Preto. Ribeirão Preto: USP, 2012. Disponível em: < https://www.fearp.usp.br/international/sobre/ribeirao-preto.html>. Acesso em: 15 jan. 2020.

VALENTE, F. L. S. Direito Humano à Alimentação, desafios e conquistas. São Paulo: Editora Cortez, 2002.

VALENTE, D. et al. Correlação espacial entre o excesso de peso, aquisição de alimentos ultraprocessados e o desenvolvimento humano no Brasil. Ciência \& Saúde Coletiva, Rio de Janeiro, v. 24, n. 3, p. 983-996, 2019.

VASCONCELOS, F. D. A. G. Combate à fome no Brasil: Uma análise histórica de Vargas a Lula. Revista de Nutricao, Campinas, v. 18, n. 4, p. 439-457, 2005.

WEBB, P. et al. Advances in Developing Country Food Insecurity Measurement Measuring Household Food Insecurity: Why It's So Important and Yet So. American Society for Nutrition, Maryland USA, v. 136, n. 2, p. 1404S-1408S, 2006.

ZIMMERMANN, C. R.; ESPÍNOLA, G. M. Programas sociais no brasil: um estudo sobre o Programa Bolsa Família no interior do Nordeste brasileiro. Caderno CRH, Salvador, v. 28, n. 73, p. 147-164, 2015. 
ANEXO I - Concordância com a realização do projeto nas unidades de saúde - Secretaria Municipal de Saúde de Ribeirão Preto, São Paulo.

\section{Prefeitura Municipal de Ribeirão Preto \\ Estado de São Paulo - Secretaria Municipal da Saúde}

OF. 3179 /2017-CAPP

CV/2017

Ribeirão Preto, 07 de agosto de 2017.

Prezado Senhor,

Informo que a gerência do CAPS III da Secretaria Municipal da Saúde manifestou a concordância com a realização do projeto de pesquisa em sua Unidade.

Sendo assim, declaro estar ciente e concordo com a realização do projeto de pesquisa: "SEGURANÇA ALIMENTAR DOMICILIAR DE FAMÍLIAS BENEFICIÁRIAS DO PROGRAMA BOLSA FAMÍLIA NO MUNICÍPIO DE RIBEIRÃO PRETO" sob a responsabilidade do Prof. Dr. LAÉRCIO JOEL FRANCO e da orientanda Vanessa Patrícia Pereira Motozo, no local supra citado.

Informo que a pesquisa somente poderá iniciar quando obtiver a aprovação do Comitê de Ética em Pesquisa da instituição proponente. Fica consignada a liberdade de esta Secretaria retirar o seu consentimento, em quaiquer fase da pesquisa, sem que isso Ihe traga prejuízo ou responsabilização de qualquer ordem.

Solicito que a pesquisadora encaminhe à Secretaria Municipal da Saúde o Relatório Final ao encerrar a pesquisa.

Cordialmente,

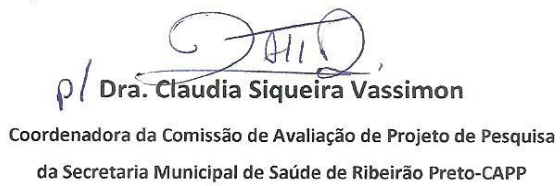

Ilustríssimo Senhor

PROF. DR. LAÉRCIO JOEL FRANCO

COORDENADOR DO PROJETO DE PESQUISA

FACULDADE DE MEDICINA DE RIBEIRAO PRETO

NESTA

Secretaria Municipal da Saúde

Comissão de Avaliação Projeto de Pesquisa

Av. Francisco Junqueira 1665, Centro, Ribeirão Preto

Fones: 39692205 / e-mail: capp@saude.pmrp.com.br 
ANEXO II - Aprovação pelo CEP Centro Saúde Escola da Faculdade de Medicina de Ribeirão Preto - FMRP/USP.

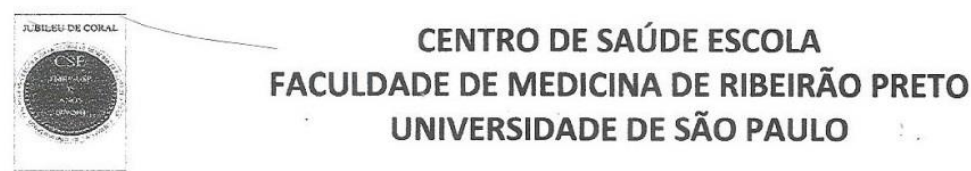

OF. 025/2017-CEP/CSE-FMRP-USP

Ribeirão Preto, 05 de Setembro de 2017.

Prezado Senhor

Comunicamos que o projeto de pesquisa abaixo especificado foi analisado e APROVADO pelo Comitê de Ética em pesquisa do Centro de Saúde Escola da Faculdade de Medicina de Ribeirão Preto da Universidade de São Paulo, na data de 05 de Setembro de 2017.

CAAE: 74053517.1 .0000 .5414

Projeto de pesquisa: "Segurança alimentar domiciliar de famílias beneficiárias do Programa Bolsa Família no município de Ribeirão Preto

Em atendimento à Resolução 466/12, deverá ser encaminhado a este CEP o relatório final da pesquisa e a publicação de seus resultados, para acompanhamento, bem como comunicada qualquer intercorrência ou a sua interrupção.

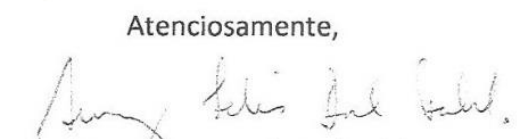

Prof. Dr. Amaury Lelis Dal Fabbro Vice-Coordenador do CEP/CSE-FMRP-USP

IImo. Prof. Dr. Laércio Joel Franco

Docente do Departamento de Medicina Social da Faculdade de Medicina de Ribeirão Preto/USP

RUA TEREZINA, № 690 - SUMAREZINHO - CEP 14055-380 - RIBEIRÃO PRETO - SP FONE: (16) 3315-0000/0001FAX: (16) 3315-0029 EMAIL: CSECUIABA@FMRP.USP.BR 
APÊNDICE I - Termo de Consentimento Livre e Esclarecido - TCLE

\section{TERMO DE CONSENTIMENTO LIVRE E ESCLARECIDO (Resolução 466/2012 do Conselho Nacional de Saúde) CÓDIGO DA FAMÍLIA: |}

\section{“SEGURANÇA ALIMENTAR DOMICILIAR DE FAMÍLIAS BENEFICIÁRIAS DO PROGRAMA BOLSA FAMÍLIA NO MUNICÍPIO DE RIBEIRÃO PRETO”}

Eu, Vanessa Patrícia Pereira Motozo, pesquisadora responsável pela presente pesquisa e aluna da Faculdade de Medicina de Ribeirão Preto da Universidade de São Paulo, situada à Av. Bandeirantes, 3900 14049-900 - Ribeirão Preto - SP, telefones $0163315-$ 2712, cel (16)988097252, junto com a Prof ${ }^{a}$ Dr $^{a}$ Luciana Cisoto Ribeiro, docente da Faculdade de Medicina de Ribeirão Preto, convidamos você a participar como voluntário(a) do projeto de pesquisa intitulado "Segurança Alimentar Domiciliar de famílias beneficiárias do Programa Bolsa Família no município de Ribeirão Preto", que tem por finalidade avaliar as famílias beneficiárias do Programa Bolsa Família segundo a condição de Segurança Alimentar. Caso concorde em participar como voluntário, você responderá a um questionário que terá duração de aproximadamente 30 minutos, sendo necessário também medir sua altura e peso bem como das crianças que moram na casa. Nenhuma das atividades que serão realizadas oferece riscos previsíveis aos participantes e se você desejar poderá deixar de participar a qualquer momento da pesquisa. A entrevista poderá causar algum constrangimento pelo fato de envolver questões relacionadas a recursos financeiros. Como a sua participação é voluntária, você tem o direito de se recusar a participar, bem como interrompê-la a qualquer momento, sem que haja qualquer tipo de punição, penalização ou interferência no recebimento do auxílio do Bolsa Família. Se participar, terá como benefício direto, o diagnóstico do seu estado nutricional e também das crianças da casa. Antes e durante toda a pesquisa, o senhor (a) tem o direito de ser esclarecido (a) sobre todos os procedimentos que participará. A pesquisadora responsável por essa pesquisa se compromete a prestar assistência integral e indenização (segundo previsto em lei) caso ocorra algum dano decorrente de sua participação na pesquisa. Não haverá remuneração por sua participação na pesquisa. As informações obtidas neste trabalho serão utilizadas apenas para esta pesquisa, portanto, garanto que manterei o sigilo sobre a sua participação e identidade. Os resultados da pesquisa serão tornados públicos por meio de apresentação em encontros científicos e publicação em periódico científico, respeitando-se sempre a privacidade e os direitos individuais dos participantes na pesquisa. Os materiais e os dados obtidos ao final da pesquisa serão arquivados em CD/DVD e HD externo sob a responsabilidade da pesquisadora Vanessa Patrícia Pereira Motozo, aluna do Departamento de Medicina Social da Faculdade de Medicina de Ribeirão Preto-USP.

Concordando com sua participação voluntaria na pesquisa, você assinará este Termo de Consentimento Livre e Esclarecido e receberá uma via deste termo, o qual consta os dados e assinatura do pesquisador responsável. Caso você tenha alguma dúvida e/ou reclamação quanto à pesquisa ou a seu desenvolvimento, além de poder perguntar ao responsável pela pesquisa, também poderá entrar em contato com o Comitê de Ética em Pesquisa do Centro de Saúde Escola - CSE/FMRP-USP, pelo telefone (16) 3315-0009.

Eu, assino este Termo de Consentimento com a finalidade de aceitar o convite e participar como sujeito da pesquisa intitulada "Segurança Alimentar Domiciliar de famílias beneficiárias do Programa Bolsa Família no município de Ribeirão Preto", de responsabilidade da pesquisadora Vanessa Patrícia Pereira Motozo, aluna do Departamento de Medicina Social da Faculdade de Medicina de Ribeirão PretoUSP e afirmo que foram dadas todas as explicações necessárias, contidas acima, para eu tomar essa decisão de livre e espontânea vontade. Aceitei participar do projeto e recebi uma via desse Termo de Consentimento Livre e Esclarecido devidamente assinada.

Ribeirão Preto,.........de de 
APÊNDICE II - Questionário

Q01. INICIAIS DO NOME:

Q02. CÓDIGO DA FAMÍLIA:

Q03. CÓDIGO DO (A) ENTREVISTADOR (A):

Q04. DATA DA ENTREVISTA:

Q05. HORA DE INÍCIO DA ENTREVISTA:

Q06. SEXO: 1 ( ) Masculino 2( ) Feminino

ANTROPOMETRIA: PESO: ___ ALTURA:

\section{BLOCO I: DADOS SÓCIOECONÔMICOS E DEMOGRÁFICOS}

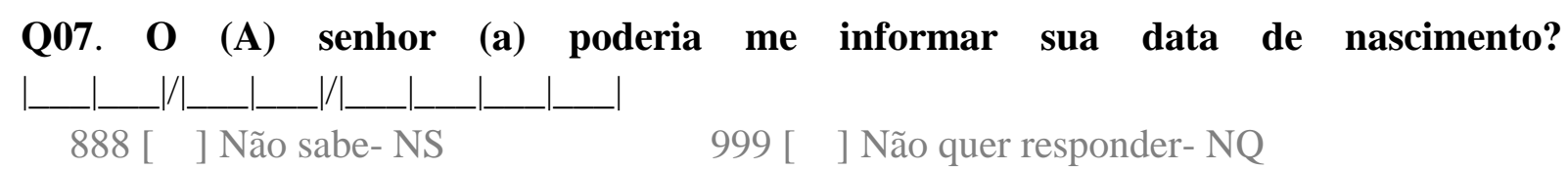

Q08. De que cor você se considera?
1 ( ) Branca
2( ) Negro
3( ) Amarela
4( ) Parda 5( ) Indígena
888 [ ] Não sabe- NS
999 [ ] Não quer responder- NQ

Q09. O (A) senhor (a) poderia me informar qual o seu grau de instrução?

1 ( ) Analfabeto

2 ( ) Fundamental I Incompleto

3 ( ) Fundamental I Completo

4 ( ) Fundamental II Incompleto

5 ( ) Fundamental II Completo

888 [ ] Não sabe- NS
6 ( ) Médio Incompleto

7 ( ) Médio Completo

8 ( ) Superior Incompleto

9 ( ) Superior Completo

999 [ ] Não quer responder- NQ

Q10. Qual o seu estado civil? (LER AS ALTERNATIVAS)
1 ( ) Solteiro (a)
3 ( ) Casado (a)
5 ( ) Viúvo (a)
2 ( ) Divorciado (a)
4 ( ) União Estável
6 ( ) Separado (a)

888 [ ] Não sabe- NS

999 [ ] ] Não quer responder- NQ

\section{Q11. Qual a sua ocupação? (LER AS ALTERNATIVAS)}

1 ( ) Desempregado

2 ( ) Aposentado

3 ( ) Trabalhador com vínculo empregatício

888 [ ] Não sabe- NS
4 ( ) Estudante

5 ( ) Profissional Liberal Autônomo

6 ( ) Do lar

999 [ ] ] Não quer responder- NQ

Q12. O (A) senhor (a) recebe outro benefício?

1 ( ) Não (Pule para a questão 13)

2( ) Sim $\longrightarrow$ Questão 12.1 Qual tipo? 
1 [ ] Cesta básica 2 [ ] Leite 888 [ ] Não sabe- NS
3 [ ] Recursos financeiros

999 [ ] Não quer responder- NQ

\section{Questão 12.2 Com que frequência ?}

1 [ ] Semanal 2 [ ]Mensal

888 [ ] Não sabe- NS

3 [ ] Exporádico

999 [ ] Não quer responder- NQ

\section{Questão 12.3 De onde ? (LER AS ALTERNATIVAS)}

$\begin{array}{rrr}1 \text { [ ] Governo } 2 \text { [ ] Igreja } & 2 \text { [ ] ONG } 3 \text { [ ] Familiares } 4 \text { [ ] Outros } \\ 888 \text { [ ] Não sabe- NS } & 999 \text { [ ] Não quer responder- NQ }\end{array}$

Q13. Qual a renda familiar ?

1 ( ) $<1$ salário mínimo 3 ( ) 2 Salários mínimo

2 ( ) 1 Salário mínimo

888 [ ] Não sabe- NS

4 ( ) $>2$ Salários mínimo

999 [ ] Não quer responder- NQ

1 salário mínimo $=\mathbf{R} \$ 937,00 *$

Q14. O (A) senhor (a) poderia me informar quanto gasta em média com alimentação?
$1($ ) $<\mathrm{R} \$ 300$
2 ( ) $\mathrm{R} \$ 300$ A 400
$3($ ) $>\mathrm{R} \$ 400$
888 [ ] Não sabe- NS
999 [ ] Não quer responder- NQ

Q15. Onde o (a) senhor (a) mora? (LER AS ALTERNATIVAS)
1 ( ) Casa própria
3 ( ) Casa alugada
2 ( ) Apartamento próprio
4 ( ) Casa de familiares
5 ( ) Outra: especifique

888 [ ] Não sabe- NS

999 [ ] Não quer responder- NQ

Q16. Qual o tipo de construção da sua residência?

1 ( ) Alvenaria acabada

3 ( ) Madeira

888 [ ] Não sabe- NS
2 ( ) Alvenaria inacabada

4 ( ) Papelão

999 [ ] Não quer responder- NQ

Q17. Quantos cômodos a sua casa possui?
1 ( ) Até 3
$2($ ) 4 a 5
3()$>6$
888 [ ] Não sabe- NS
999 [ ] Não quer responder- NQ

Cômodo*: repartição por meio de paredes de uma casa.

Q18. Há abastecimento de água por rede pública?

1 ( ) Sim 2( ) Não

888 [ ] Não sabe- NS 999 [ ] Não quer responder- NQ

Q19. Há coleta de lixo pelo serviço público?

1 ( ) Sim 2( ) Não

888 [ ] Não sabe- NS

999 [ ] Não quer responder- NQ 
Q20. O (A) senhor (a) possui filtro de água em casa?

$1($ ) $\operatorname{Sim}$

2 ( ) Não

888 [ ] Não sabe- NS

999 [ ] Não quer responder- NQ

Agora vou fazer algumas perguntas sobre itens do domicilio para efeito de classificação econômica. Todos os itens de eletroeletrônicos que vou citar devem estar funcionando, incluindo os que estão guardados. Caso não estejam funcionando, considere apenas se tiver intenção de consertar ou repor nos próximos seis meses.

\begin{tabular}{|l|c|c|c|c|c|}
\hline Itens & $\mathbf{0}$ & $\mathbf{1}$ & $\mathbf{2}$ & $\mathbf{3}$ & $\mathbf{4}$ ou + \\
\hline Banheiros & 0 & 3 & 7 & 10 & 14 \\
\hline Empregados Domésticos & 0 & 3 & 7 & 10 & 13 \\
\hline Automóveis & 0 & 3 & 5 & 8 & 11 \\
\hline Microcomputador & 0 & 3 & 6 & 8 & 11 \\
\hline Lava Louça & 0 & 3 & 6 & 6 & 6 \\
\hline Geladeira & 0 & 2 & 3 & 5 & 5 \\
\hline Freezer & 0 & 2 & 4 & 6 & 6 \\
\hline Lava Roupa & 0 & 2 & 4 & 6 & 6 \\
\hline DVD & 0 & 1 & 3 & 4 & 6 \\
\hline Micro-ondas & 0 & 2 & 4 & 4 & 4 \\
\hline Motocicleta & 0 & 1 & 3 & 3 & 3 \\
\hline Secadora de Roupa & 0 & 2 & 2 & 2 & 2 \\
\hline
\end{tabular}

Qual é o grau de instrução do chefe da família? Considere como chefe da família a pessoa que contribui com a maior parte da renda do domicílio.

\begin{tabular}{|l|c|}
\hline Analfabeto/ Fundamental I Incompleto & 0 \\
\hline Fundamental I Completo/ Fundamental II Incompleto & 1 \\
\hline Fundamental II Completo/ Médio incompleto & 2 \\
\hline Médio completo/ Superior Incompleto & 4 \\
\hline Superior Completo & 7 \\
\hline
\end{tabular}

\begin{tabular}{|l|c|c|}
\hline & Não & Sim \\
\hline Água Encanada & 0 & 4 \\
\hline Rua Pavimentada & 0 & 2 \\
\hline
\end{tabular}

Soma:

Classe Econômica: 


\section{BLOCO II: CONHECIMENTO SOBRE O PROGRAMA BOLSA FAMÍLIA}

Q21. Como soube da existência do Programa Bolsa Família?

1 ( ) Televisão/ rádio

3 ( ) Internet

2 ( ) Amigos/ familiares

4 ( ) Outros

5 ( ) Informativo (folhetos)

888 [ ] Não sabe- NS

999 [ ] Não quer responder- NQ

Q22. Para que o (a) senhor (a) usa o benefício do Programa Bolsa Família?

1 ( ) Comprar alimentos

3 ( ) Comprar roupas

2( ) Comprar materiais escolares

4 ( ) Outros

888 [ ] Não sabe- NS

999 [ ] Não quer responder- NQ

Q23. Quem frequenta a unidade de saúde?
1 ( ) Beneficiário
2 ( ) Idoso
3 ( ) Família
888 [ ] Não sabe- NS
999 [ ] Não quer responder- NQ

Q24. Com que frequência o (s) beneficiário (s) comparece(m) a unidade de saúde 1 ( ) Acompanhamento com consultas agendadas.

2 ( ) Somente para a pesagem do Bolsa Família

888 [ ] Não sabe- NS 999 [ ] Não quer responder- NQ 


\section{BLOCO III: AVALIACÃO DA INSEGURANCA ALIMENTAR E NUTRICIONAL}

1 - Nos últimos três meses, os moradores deste domicílio tiveram preocupação de que os alimentos acabassem antes de poderem comprar ou receber mais comida?
$\square$ Sim
$\square$ Não
$\square$ Não sabe/Não quis responder

2 - Nos últimos três meses, os alimentos acabaram antes que os moradores deste domicílio tivessem dinheiro para comprar mais comida?
$\square$ Sim
$\square$ Não
$\square$ Não sabe/Não quis responder

3 - Nos últimos três meses, os moradores deste domicílio ficaram sem dinheiro para ter uma alimentação saudável e variada?

$\square$ Sim $\square$ Não $\square$ Não sabe/Não quis responder

4 - Nos últimos três meses, os moradores deste domicílio comeram apenas alguns alimentos que ainda tinham porque o dinheiro acabou?
$\square$ Sim
$\square$ Não
$\square$ Não sabe/Não quis responder

5 - Nos últimos três meses, algum morador de 18 anos ou mais de idade deixou de fazer uma refeição porque não havia dinheiro para comprar comida?
$\square$ Sim
Não
Não sabe/Não quis responder

6 - Nos últimos três meses, algum morador de 18 anos ou mais de idade, alguma vez comeu menos do que devia porque não havia dinheiro para comprar comida?
$\square$ Sim
$\square$ Não
$\square$ Não sabe/Não quis responder

7 - Nos últimos três meses, algum morador de 18 anos ou mais de idade, alguma vez sentiu fome, mas não comeu, porque não havia dinheiro para comprar comida?

$\square \operatorname{Sim} \square$ Não $\square$ Não sabe/Não quis responder

8 - Nos últimos três meses, Algum morador de 18 anos ou mais de idade, alguma vez, fez apenas uma refeição ao dia ou ficou um dia inteiro sem comer porque não havia dinheiro para comprar comida?
$\square$ Sim
$\square$ Não
$\square$ Não sabe/Não quis responder

9 - Nos últimos três meses, algum morador com menos de 18 anos de idade, alguma vez, deixou de ter uma alimentação saudável e variada porque não havia dinheiro para comprar comida?
$\square$ Sim
$\square$ Não
$\square$ Não sabe/Não quis responder

10 - - Nos últimos três meses, algum morador com menos de 18 anos de idade, alguma vez, não comeu quantidade suficiente de comida porque não havia dinheiro para comprar comida?
$\square$ Sim
$\square$ Não
$\square$ Não sabe/Não quis responder

11 - Nos últimos três meses, alguma vez, foi diminuída a quantidade de alimentos das refeições de algum morador com menos de $\mathbf{1 8}$ anos de idade, porque não havia dinheiro para comprar comida?
$\square$ Sim
$\square$ Não
$\square$ Não sabe/Não quis responder

12 - Nos últimos três meses, alguma vez, algum morador com menos de 18 anos de idade deixou de fazer alguma refeição, porque não havia dinheiro para comprar comida?

$\square$ Sim $\square$ Não $\square$ Não sabe/Não quis responder

13 - Nos últimos três meses, alguma vez, algum morador com menos de 18 anos de idade, sentiu fome, mas não comeu porque não havia dinheiro para comprar comida?
$\square \mathrm{Sim}$
$\square$ Não
Não sabe/Não quis responder

14 - Nos últimos três meses, alguma vez, algum morador com menos de 18 anos de idade, fez apenas uma refeição ao dia ou ficou sem comer por um dia inteiro porque não havia dinheiro para comprar comida?
Sim
$\square$ Não
$\square$ Não sabe/Não quis responder

PONTUAÇÃO:

CLASSIFICAÇÃO: 
BLOCO IV: COMPOSICÃO FAMILIAR

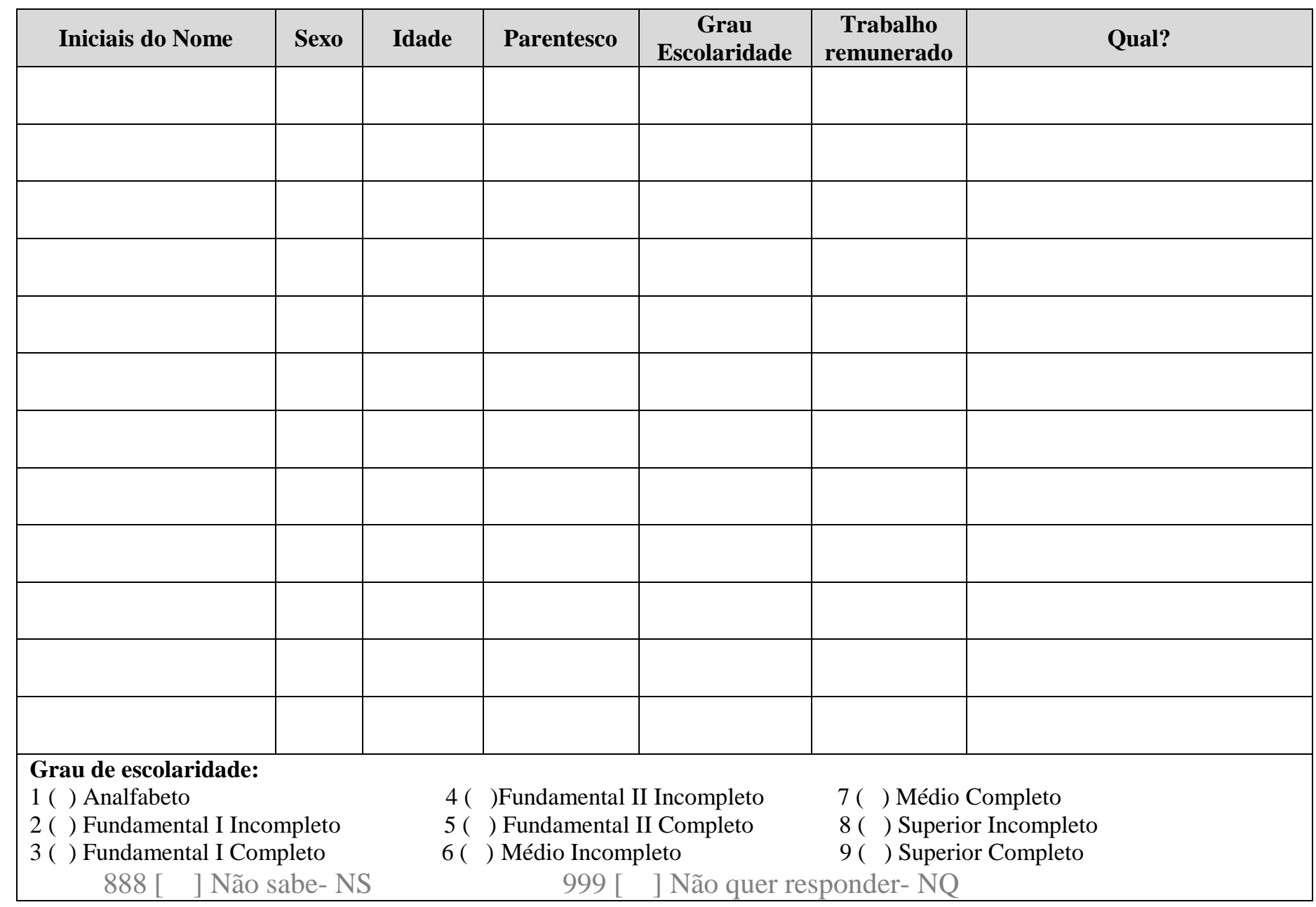

\section{BLOCO V: DADOS DAS CRIANCAS}

\begin{tabular}{|c|c|c|c|c|c|}
\hline NOME & SEXO & $\begin{array}{c}\text { DATA } \\
\text { NASCIMENTO }\end{array}$ & $\begin{array}{c}\text { FREQÜENTA } \\
\text { CRECHE/ESCOLA }\end{array}$ & PESO & ALTURA \\
\hline & & & & & \\
\hline & & & & & \\
\hline & & & & & \\
\hline & & & & & \\
\hline & & & & & \\
\hline & & & & & \\
\hline
\end{tabular}

AGRADECER AO PARTICIPANTE E ENCERRAR A ENTREVISTA.

HORA DE ENCERRAMENTO DA ENTREVISTA: |_____ $\mid$ 